\title{
Improved antimalarial activity of caprol-based nanostructured lipid carriers encapsulating artemether-lumefantrine for oral administration
}

\author{
Paul Achile Akpa ${ }^{1}$, Joseph Abuchi Ugwuoke ${ }^{1}$, Anthony Amaechi Attama ${ }^{1}$, \\ Chinenye Nnenna Ugwu², Ezinwanne Nneoma Ezeibe², Mumuni Audu Momoh², \\ Adaeze Chidiebere Echezona ${ }^{1}$, Franklin Chimaobi Kenechukwu ${ }^{1}$
}

1. Department of Pharmaceutics, University of Nigeria, Nsukka.

2. Department of Pharmaceutical Microbiology and Biotechnology, University of Nigeria, Nsukka.

\begin{abstract}
Background: Artemether and lumefantrine display low aqueous solubility leading to poor release profile; hence the need for the use of lipid-based systems to improve their oral bioavailability so as to improve their therapeutic efficacy.

Aim and objective: The objective of this work was to utilize potentials of nanostructured lipid carriers (NLCs) for improvement of the oral bioavailability of artemether and lumefantrine combination and to evaluate its efficacy in the treatment of malaria. This study reports a method of formulation, characterization and evaluation of the therapeutic efficacies of caprol-based NLC delivery systems with artemether and lumefantrine.

Method: The artemether-lumefantrine co-loaded NLCs were prepared using the lipid matrix $(5 \% \mathrm{w} / \mathrm{w})$ (containing beeswax and Phospholipon ${ }^{\circledR} 90 \mathrm{H}$ and Caprol-PGE 860$)$, artemether $(0.1 \% \mathrm{w} / \mathrm{w})$ and lumefantrine $(0.6 \% \mathrm{w} / \mathrm{w})$, sorbitol $(4 \% \mathrm{w} / \mathrm{w})$, Tween ${ }^{\circledR} 80(2 \% \mathrm{w} / \mathrm{w}$ as surfactant) and distilled water (q.s to $100 \%)$ by high shear homogenization and evaluated for physicochemical performance. The in vivo antimalarial activities of the NLC were tested in chloroquine-sensitive strains of Plasmodium berghei (NK-65) using Peter's 4-day suppressive protocol in mice and compared with controls. Histopathological studies were also carried out on major organs implicated in malaria.

Results: The NLC showed fairly polydispersed nano-sized formulation (z-average:188.6 nm; polydispersity index, PDI $=0.462$ ) with no major interaction occurring between the components while the in vivo study showed a gradual but sustained drug release from the NLC compared with that seen with chloroquine sulphate and Coartem ${ }^{\circledR}$. Results of histopathological investigations also revealed more organ damage with the untreated groups than groups treated with the formulations. Conclusion: This study has shown the potential of caprol-based NLCs for significant improvement in oral bioavailability and hence antimalarial activity of poorly soluble artemether and lumefantrine. Importantly, this would improve patient compliance due to decrease in dosing frequency as a sustained release formulation.
\end{abstract}

Keywords: Nanostructured lipid carriers; artemether-lumefantrine; malaria; Caprol.

DOI: https://dx.doi.org/10.4314/ahs.v20i4.20

Cite as: Akpa PA, Ugwnoke JA, Attama AA, Ugwn CN, Ezeibe EN, Momoh MA, et al. Improved antimalarial activity of caprol-based nanostructured lipid carriers encapsulating artemether-lumefantrine for oral administration. Afri Health Sci. 2020;20(4):1679-97. bttps:// dx.doi.org/10.4314/abs.v20i4.20

\section{Introduction}

Malaria, a common parasitic vector-borne poverty-related disease caused by the bite of infected mosquitoes, affects the quality of life of millions of people in malar-
Corresponding authors:
PA Akpa,
Department of Pharmaceutics,
University of Nigeria, Nsukka.
Emai:paul.akpa@unn.edu.ng;
Or
Kenechukwu FC,
Department of Pharmaceutics,
University of Nigeria, Nsukka.
Email: frankline.kenechukwu@unn.edu.ng

ia endemic regions of the world and is the leading cause of mortality and morbidity in the developing world ${ }^{1}$. Many obstacles lie in the face of the effective control of malaria, including the plethora of antigenic variations coupled with antigenic polymorphism ${ }^{2}$ and wide range of mechanisms by means of which the causative agent evades the host immune system, which hinders vaccine production effort ${ }^{\mathrm{s}}$. Furthermore, efforts at vector control have only yielded marginal results.

The resistance of Plasmodium falciparum to most of the widely employed antimalarial agents such as sulphadoxine-pyrimethamine, chloroquine, mefloquine and amodiaquine sets further limits to disease elimination efforts. The oral bioavailability of most antimalarials is low ${ }^{4}$. The rising incidence of parasite resistance and the paucity of novel drug candidates in the pipeline of 
the global pharmaceutical sector makes it necessary for the exploitation of other modes of drug formulation with the objective of developing drug delivery systems with desirable features that can culminate in safe and effective medicines with better therapeutic outcomes utilizing the currently available active pharmaceutical ingredients (APIs). Nanomedicines could help to overcome the limitations of currently utilized antimalarial agents, including low intracellular concentrations ${ }^{5}$ and toxicity ${ }^{6}$.

The World Health Organization (WHO) strongly recommends the use of artemisinin-based combination therapies (ACTs) in a bid to overcome the development of resistance to the drugs by the malaria parasite ${ }^{7}$. Artemether- lumenfantrine (ARM-LFN) combination is one of the most popular combinations and the first line fixed-dose ACTs prescribed by the WHO for oral treatment of uncomplicated malaria ${ }^{8}$. In this combination, artemether exerts rapid onset of action though of short duration of action whereas lumefantrine exhibits a relatively slower action and it has a longer halflife and thus persists longer in the systemic blood circulation ${ }^{9}$. Artemether effects an almost instantaneous symptomatic relief as it brings about a reduction in the parasite burden while lumefantrine neutralizes any parasite remnants ${ }^{10}$. The use of these two agents together forecloses contact of the parasites with either of the drugs alone thus reducing the likelihood of resistance developing to these agents. Combination products operate synergistically to effect a reduction in gametocyte carriage and this further hinders transmission of the causative parasite. It has been established that the artemether-lumefantrine combination has poor aqueous solubility as well as low oral bioavailability ${ }^{11}$.

Nanocarriers have been shown to enhance dissolution of poorly soluble drugs owing to their large surface area $^{12}$. Lipid based drug delivery systems (LBDDS) boost oral bioavailability of lipophilic drugs via numerous mechanisms ${ }^{13-16}$. First, the ingestion of LBDDS triggers contractions of the gall bladder and elicits an increase in biliary and pancreatic secretions like bile salts, cholesterol and phospholipids. These secretions together with gastric shear lead to the formation of a crude emulsion which maintains the drug in a solubilized form affording better gastrointestinal absorption $^{17}$. The surfactants and co-surfactants present in the LBDDS further augment the solubility of poorly soluble drugs ${ }^{18}$. Secondly, it is established that some excipients including surfactants such as Tween ${ }^{\circledR} 80$ and Solutol ${ }^{\mathbb{B}} \mathrm{HS} 15$ when present in a LBDDS restrain intestinal cytochrome P450 enzymes which catalyze pre-systemic metabolism ${ }^{19}$. Certain lipids containing large chain fatty acids or those with a high degree of unsaturation bring on lymphatic uptake of LBDDS which facilitates avoidance of the hepatic first-pass metabolism of the drug in question ${ }^{20}$.

NLCs are second generation of LBDDS, and they were chosen due to their advantages such as enhanced drug loading, cost effectiveness, nontoxicity over the other types of lipid carriers such as liposomes, nanoemulsions, microemulsions and solid lipid nanocarriers ${ }^{17}$. The purpose of an NLC formulation is to produce particles in which the oil is incorporated into the core of the solid lipid and the drug is solubilized in the oily core. This should result in a higher loading capacity, encapsulation efficiency, and controlled drug release as the drug dissolves in the oil and simultaneously encapsulates in the solid lipid, which should also lead to slower polymorphic transition and lower crystallinity index (higher stability) ${ }^{18}$. Furthermore, co-loaded nanoparticles are preferred over the single drug-loaded nanoparticles because co-loading has been shown to increase the therapeutic efficiency of drugs by increasing protection rate, reducing the drug dosage, etc. ${ }^{17}$. Although we have developed LBDDS of artemether and lumefantrine in our earlier studies ${ }^{21-23}$, to the best of our knowledge, there is paucity of information in the literature on the use of phospholipid-modified caprol-based NLC for co-delivery of artemether and lumefantrine. Consequently, the purpose of this work was to formulate and evaluate a nanostructured lipid carrier (NLC) using a combination of solid lipids (beeswax and Phospholipon ${ }^{\circledR} 90 \mathrm{G}$ ) and a liquid lipid (Caprol PGE 860) for the entrapment of the lipophilic drugs artemether and lumefantrine. The NLCs produced were characterized to assess fundamental physicochemical attributes such as the particle size and zeta potential, morphology, thermal properties, compatibility and stability. The in vivo antimalarial study was performed in Wistar mice infected with Plasmodium berghi using Peter's protocol while haematological properties as well as the histopathology of key organs of the mice were evaluated.

\section{Materials and methods \\ Materials}

Artemether was obtained from Hangzhou Dayang Chemical Co. Ltd. (Zhejiang, China), while lumefantrine was sourced from Guilin Pharmaceutical Co Ltd. (Shanghai, China). Phospholipon ${ }^{\circledR} 90 \mathrm{H}$ (P90H) (Phospholipid GmbH, Köln,, Germany), sorbitol (Caesar 
\&Loretz, Hilden,Germany), sorbic acid (Foodchem Int. Co., China), beeswax (Carl Roth, Karlsruhe, Germany), Polysorbate 80 (Tween $^{\circledR}$ 80) (Acros Organics, Geel, Belgium), Capryol-PGE 860 (Abitech Corp, USA), Coartem ${ }^{\circledR}$ (Novartis, Basel, Switzerland) and distilled water (Lion water, University of Nigeria, Nsukka, Nigeria) and other solvents and reagents were used as procured from their manufacturers without further $\mathrm{pu}-$ rification.

Adult albino Wistar mice of both sexes infected with Plasmodium berghei(NK 65) malaria parasites were employed in the study.

\section{Methods \\ Preparation of lipid matrix for nanostructured li- pid carrier formulation}

Lipid matrix was prepared by the fusion method ${ }^{21}$ using beeswax and Phospholipon ${ }^{\circledR} 90 \mathrm{H}$ (as solid lipids) in combination with caprol-PGE 860 (as liquid lipid). The solid lipids and liquid lipid were used at 7:3 ratio (i.e. $21.0 \mathrm{~g}$ of $\mathrm{BW} / \mathrm{P} 90 \mathrm{H}$ admixture and $9.0 \mathrm{~g}$ of caprolPGE 860). First of all, the solid lipids (at 7:3 ratio of $\mathrm{BW}$ and $\mathrm{P} 90 \mathrm{H})(21.0 \mathrm{~g}$ of beeswax and $9.0 \mathrm{~g}$ of $\mathrm{P} 90 \mathrm{H})$ were weighed, added in a glass beaker placed inside an oil bath (liquid paraffin) and melted together in the temperature-regulated bath at a temperature of $70{ }^{\circ} \mathrm{C}$. The mixture was stirred continuously until a homogenous, transparent colourless melt was obtained. The homogenous mixture of the lipid matrix was stirred further at room temperature until solidification. After 24 hours, this lipid matrix was melted in the temperature-regulated bath at a temperature of $80^{\circ} \mathrm{C}$ followed by addition of $9.0 \mathrm{~g}(8.98 \mathrm{ml})$ of caprol-PGE 860 . The mixture was stirred continuously until a homogenous, transparent white melt was obtained. The homogenous mixture of the lipid matrix was stirred at room temperature until solidification. The lipid matrix was then stored in airtight and moisture resistant glass bottle in the refrigerator until used.

\section{Preparation of drug-loaded lipid matrix}

Drug-loaded lipid matrix was prepared by fusion ${ }^{22}$ using the lipid matrix, artemether and lumefantrine. With target lipid concentration of $5.0 \% \mathrm{w} / \mathrm{w}$ and target drug concentrations of $0.1 \% \mathrm{w} / \mathrm{w}$ of artemether and $0.6 \% \mathrm{w} / \mathrm{w}$ of lumefantrine in the nanostructured lipid carrier (NLC) to be developed, $5 \mathrm{~g}$ of the lipid matrix (LM3) was melted in the temperature-regulated oil bath at a temperature of $80{ }^{\circ} \mathrm{C}$ followed by addition of $0.1 \mathrm{~g}$ of artemether and $0.6 \mathrm{~g}$ of lumefantrine. The mixture was stirred continuously until a homogenous, transparent white melt was obtained. The homogenous mixture of the drug-loaded lipid matrix was stirred further at room temperature until solidification. It was then stored in airtight and moisture resistant glass bottle in the refrigerator until used.

\section{Differential scanning calorimetry (DSC) analysis of plain and drug-loaded lipid matrices}

Melting transitions and changes in heat capacity of the lipid matrix of beeswax and $\mathrm{P} 90 \mathrm{H}$ structured with Caprol-PGE 860, artemether, lumefantrine and drug-loaded lipid matrix were determined using a differential scanning calorimeter (DSC Q100 TA Instrument, Germany).

A $5 \mathrm{mg}$ quantity of each sample was weighed into an alu $\neg$ minum pan, hermetically sealed and the thermal behaviour determined in the range of 20 to $350{ }^{\circ} \mathrm{C}$ at a heating rate of $5^{\circ} \mathrm{C} / \mathrm{min}$. The temperature was held at $80{ }^{\circ} \mathrm{C}$ for $10 \mathrm{~min}$ and thereafter, cooled at the rate of 5 to $10^{\circ} \mathrm{C} / \mathrm{min}$. Baselines were determined using an empty pan, and all the thermograms were baseline-corrected.

\section{Fourier transform infra-red (FT-IR) spectroscopic analysis of plain and drug-loaded lipid matrices}

FT-IR spectroscopic analysis was conducted on the lipid matrix of beeswax and P90H, Caprol-PGE 860, lipid matrix structured with Caprol-PGE 860, artemether, lumefantrine and drug-loaded lipid matrix of beeswax and $\mathrm{P} 90 \mathrm{H}$ structured with Caprol-PGE 860 using a Shimadzu FT-IR 8300 Spectrophotometer (Shimadzu, Tokyo, Japan) and the spectrum was recorded in the wavelength region of 4000 to $400 \mathrm{~cm}-1$ with threshold of 1.303 , sensitivity of 50 and resolution of $2 \mathrm{~cm}-1$ range. A smart attenuated total reflection (SATR) accessory was used for data collection. The potassium bromate $(\mathrm{KBr})$ plate used for the study was cleaned with a tri-solvent (acetone-toluene-methanol at 3:1:1 ratio) mixture for baseline scanning. A $0.1 \mathrm{~g}$ quantity of each sample was mixed with $0.1 \mathrm{ml}$ nujol diluent. The solution was introduced into the potassium bromate $(\mathrm{KBr})$ plate and compressed into discs by applying a pressure of 5 tons for $5 \mathrm{~min}$ in a hydraulic press. The pellet was placed in the light path and the spectrum obtained. Spectra were collected in 60 s using Gram A1 spectroscopy software, and the chemometrics were performed using TQ Analyzer'. 
Preparation of nanostructured lipid carrier (NLC) Caprol-based nanostructured lipid carrier (NLC) encapsulating artemether and lumefantrine were prepared using the drugs, lipid matrix, Polysorbate ${ }^{\circledR} 80$ (Tween ${ }^{\circledR}$ 80) (mobile surfactant), sorbitol (cryoprotectant) and distilled water (vehicle) by the high shear hot homogenization method ${ }^{21-23}(5 \% \mathrm{w} / \mathrm{w}$ of the LC (lipid matrix)formulation) was placed in glass beaker and melted at $80{ }^{\circ} \mathrm{C}$ on the temperature-regulated hotplate (IKA instruments, Germany) and the drugs $(0.1 \% \mathrm{w} / \mathrm{w}$ of artemether and $0.6 \% \mathrm{w} / \mathrm{w}$ of lumefantrine) were added to the melted lipid matrix. Aqueous surfactant solution consisting of sorbitol $(4 \% \mathrm{w} / \mathrm{w})$ and Polysorbate ${ }^{\circledR} 80$ $(2 \% \mathrm{w} / \mathrm{w})$ was prepared in a beaker and heated at the same temperature. The hot aqueous surfactant phase was then dispersed in the hot lipid phase (oily phase) using a high-speed homogenizer (Ultra-Turrax T25) (IKA-Werke, Staufen, Germany) at $1000 \mathrm{rpm}$ for $5 \mathrm{~min}$. The obtained pre-emulsion was homogenized at 15,000 rpm for $30 \mathrm{~min}$, and allowed to cool or re-crystallize at room temperature. The formulation composition of the NLC is shown in Table 1.

Table 1: Optimized formula for the preparation of the nanostructured lipid carrier

\begin{tabular}{|l|l|l|}
\hline S/No & Ingredient & $\mathbf{\%} \mathbf{w} / \mathbf{w}$ \\
\hline 1 & $\begin{array}{l}\text { Lipid matrix (Beeswax + Phospholipon 90H+Caprol-PGE } \\
860)\end{array}$ & 5.0 \\
\hline 2 & Artemether/lumefantrine & $0.1 / 0.6$ \\
\hline 3 & ${\text { Polysorbate } 80\left(\text { Tween }^{8} 80\right)}^{8}$ & 2.0 \\
\hline 4 & Sorbitol $^{8}$ & 4.0 \\
\hline 5 & Distilled water & q.s. to 100 \\
\hline
\end{tabular}

Characterization of the nanostructured lipid carrier (NLC)

\section{Particle size and polydispersity index}

Mean diameter, Z. Ave (nm) and polydispersity index (PDI) of the NLC were measured using a zetasizer nano-ZS (Malvern Instrument, Worceshtire, UK) equipped with a $10 \mathrm{mw}$ He-NE laser employing the wavelength of $633 \mathrm{~nm}$ and a backscattering angle of $173^{\circ}$ at $25^{\circ} \mathrm{C}$. The sample was diluted with double-distilled water to obtain a suitable scattering intensity, before photon correlation spectroscopic (PCS) analysis. Zeta potential was also determined.

\section{Compatibility study by Fourier transform infra-red} (FT-IR) spectroscopy for the NLC formulation

Fourier transform infra-red (FT-IR) spectroscopic analysis using a Shimadzu FT-IR 8300 Spectrophotometer (Shimadzu, Tokyo, Japan) and the spectrum was recorded in the wavelength region of 4000 to $400 \mathrm{~cm}-1$ with threshold of 1.303 , sensitivity of 50 and resolution of 2 cm-1 range. A smart attenuated total reflection (SATR) accessory was used for data collection. The potassium bromate $(\mathrm{KBr})$ plate used for the study was cleaned with a tri-solvent (acetone-toluene-methanol at 3:1:1 ratio) mixture for baseline scanning. A $0.1 \mathrm{ml}$ volume of the NLC was mixed with $0.1 \mathrm{ml}$ nujul diluent. The solution was introduced into the potassium bromate $(\mathrm{KBr})$ plate and compressed into discs by applying a pressure of 5 tons for $5 \mathrm{~min}$ in a hydraulic press. The pellet was placed in the light path and the spectrum obtained. Spectra were collected in $60 \mathrm{~s}$ using Gram A1 spectroscopy software, and the chemometrics was performed using TQ Analyzer'.

\section{Antimalarial and hematological studies on the for- mulations}

Firstly, 20 adult albino Wistar mice of both sexes were procured, housed, and fed normally to acclimatize to the laboratory environment of the Faculty of Veterinary Medicine, University of Nigeria, Nsukka. The parasite, a chloroquine-sensitive strain of Plasmodium berghei NK 65 which was maintained in mice, was obtained from the Nigerian Institute of Medical Research (NIMR), Yaba, Lagos. Evaluation of the curative potential (in vivo anti-plasmodial activity) of the formulations against established plasmodium infection was carried out according to standard protocols established by Peter et al. ${ }^{24}$. Briefly, the mice were divided into four groups of five mice each. Blood of the donor mice was collected by cardiac puncture and diluted with physi- 
ological saline (normal saline) to give a concentration of $1 \times 10^{8}$ parasitized erythrocytes per mL. Ab initio, on day 0 of the test, percentage parasitemia of the donor mice was determineby Giemsa-stained thin blood smear of the donor mice. A $0.2 \mathrm{~mL}$ volume of the donor mouse erythrocyte equivalent to $2 \times 10^{7}$ parasitized erythrocytes was injected intraperitoneally into each of the experimental mice on day 1 . All the mice were inoculated with chloroquine sensitive strain of Plasmodium berghei (NK 65) and left untreated until the third day post inoculation to ensure establishment of plasmodium infection.

Post inoculation, all treatments were given orally per day for 3 days (day 4 to day 6). On day 1 of treatment (day 4), mice from the negative control group were administered with $0.2 \mathrm{~mL} / \mathrm{kg}$ body weight of distilled water, while mice from the first positive control group received $10 \mathrm{mg} / \mathrm{kg}$ body weight of chloroquine phosphate tablet dispersed in distilled water, then $5 \mathrm{mg} / \mathrm{kg}$ on day 2 and 3 of treatment (day 5 and day 6). Mice from the second positive control group received 4 and $24 \mathrm{mg} / \mathrm{kg}$ of commercial fixed combination dose of artemether-lumefantrine (1:6) $\left(\right.$ coartem $\left.^{\circledR}\right)$ once daily. The other group received NLC formulation (M0) containing 4 and $24 \mathrm{mg} / \mathrm{kg}$ of artemether and lumefantrine (1:6). These dosages have been employed by previous researchers who evaluated the antimalarial activity of solid lipid nanoparticles loaded with artemether and lumefantrine in Plasmodium berghei-infected mice (21). The animals were randomized equally into four groups as follows:

Group 1: infected control (negative control) (infected but untreated)

Group 2: infected and treated with chloroquine phosphate (first positive control)

Group 3: infected and treated with coartem ${ }^{\circledR}$ (second positive control)

Group 4: infected and treated with NLC (M0).

Parasitemia was determined 3, 7 and 14 days after treatment. Each mouse was tail-bled and a thin blood film was made on a microscope slide. The films were stained with $10 \%$ Giemsa solution and examined microscopically to monitor the parasitemia level. Percentage parasitemia count in each animal was calculated using equation 1. Thereafter, mean parasitemia in each group was determined. The antimalarial activity in each group was determined using equation 2 .

Parasitemia count in each animal $(\%)=\frac{\text { No of infected } R B C}{\text { Total no of } R B C} \times 100 \quad$......Eqn 1

Reduction in parasitemia $(\%)=\frac{\text { Mean pretreatment parasitemia }- \text { Mean postreatment parasitemia }}{\text { Mean pretreatment parasitemia }} \times 100$.. Eqn 2
The weight of the animals, hemoglobin concentration $(\mathrm{Hb})$ and packed cell volume (PCV) were also monitored before inoculation, after inoculation, before treatment and after treatment up to the $14^{\text {th }}$ day after treatment. Moreover, the survivability of mice treated with the formulations was also determined.

\section{Histopathological (histological) studies on the for- mulations}

The mice were sacrificed on the fifteenth day post treatment and the liver and kidney of a mouse from each group subjected to histological studies. Tissue sections of the liver and kidney of mouse from each group were fixed in $10 \%$ normal saline and dehydrated in ascending grades of ethanol. Thereafter, the tissues were cleared in chloroform overnight, infiltrated and embedded in molten paraffin wax. The blocks were later trimmed and sectioned at 5-6 $\mathrm{mm}$. The sections were deparaffinized in xylene, rinsed with water and subsequently stained with Haematoxylin and Eosin ( $\mathrm{H}$ and E) and fixed for viewing which was done with a moticam (D-MOTICAM 580, U.S) fitted to the polarized photomicroscope.

\section{Storage stability studies of the formulations}

The NLC formulation was also subjected to time-resolved $\mathrm{pH}$ analysis for three months to check the effect of storage on the stability of the NLC formulation. The $\mathrm{pH}$ of the formulation was determined using a $\mathrm{pH}$ meter (Suntex TS-2, Taiwan) after one day, one week, one month and three months of storage at room temperature $\left(28 \pm 3{ }^{\circ} \mathrm{C}\right)$.

\section{Statistical analysis}

All experiments were performed in replicates for validity of statistical analysis. Results were expressed as mean \pm SD. ANOVA and Student's t-test were performed on the data sets generated using SPSS. Differences were considered significant for $\mathrm{p}$-values $<0.05$.

\section{Results and discussion}

Nanostructured lipid carriers (NLCs) are an attractive approach for the delivery of highly lipophilic drugs such as artemether and lumefantrine as NLCs have advantages over other colloidal systems - solid lipid microparticles, solid lipid nanoparticles, liposomes, nanoemulsions, and microemulsions ${ }^{25}$. This is because the majority of drugs have higher solubility in liquid lipids (oils) rather than solid lipids. The purpose of NLC formulation is to produce particles in which the oil is incorporated into the core of the solid lipid and the 
drug is solubilized in the oily core. This should result in a higher loading capacity, encapsulation efficiency, and controlled drug release as the drug dissolves in the oil and simultaneously encapsulates in the solid lipid; which should also lead to slower polymorphic transition and lower crystallinity index (higher stability) ${ }^{25}$. Beeswax is a hard fat and a high melting point lipid for modified oral dosage forms, in addition to being a consistency agent (thickener) for topical formulations. Phospholipon $^{\circledR} 90 \mathrm{H}(\mathrm{P} 90 \mathrm{H})$ is a phospholipid and an amphiphilic surface modifier used for oral, parenteral and topical formulations. Combination of lipophilic and hydrolipophilic (amphiphilic) surfactants yields better stabilization of dispersed systems. Consequently, beeswax was structured with a phospholipid, $\mathrm{P} 90 \mathrm{H}$, whereas caprol served as the liquid lipid to improve the solu- bilization of the drugs - artemether and lumefantrine. High oil content of NLC has been associated with less crystallinity ${ }^{26}$. Caprol-based nanostructured lipid carrier (NLC) encapsulating artemether and lumefantrine were prepared using the drugs, lipid matrix, Polysorbate ${ }^{\circledR} 80$ (Tween ${ }^{\circledR} 80$ ) (mobile surfactant), sorbitol (cryoprotectant) and distilled water (vehicle) by the high shear hot homogenization method. NLC produced had average particle size of $188 \pm 6 \mathrm{~nm}$ and polydispersity index (PDI) of $0.462 \pm 4$. Such a small particle size was obtained by precluding destabilization owing to creaming and controlling sedimentation caused by Brownian motion ${ }^{27}$. Details of the particle size analysis are shown in Figure 1. The PDI value of 0.462 is substantially high. It shows that the NLC is fairly polydispersed and indicates a broad particle size distribution ${ }^{28}$. This is in agreement with the findings of other workers ${ }^{29-35}$.

\section{Size Distribution Report by Intensity 422

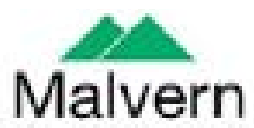

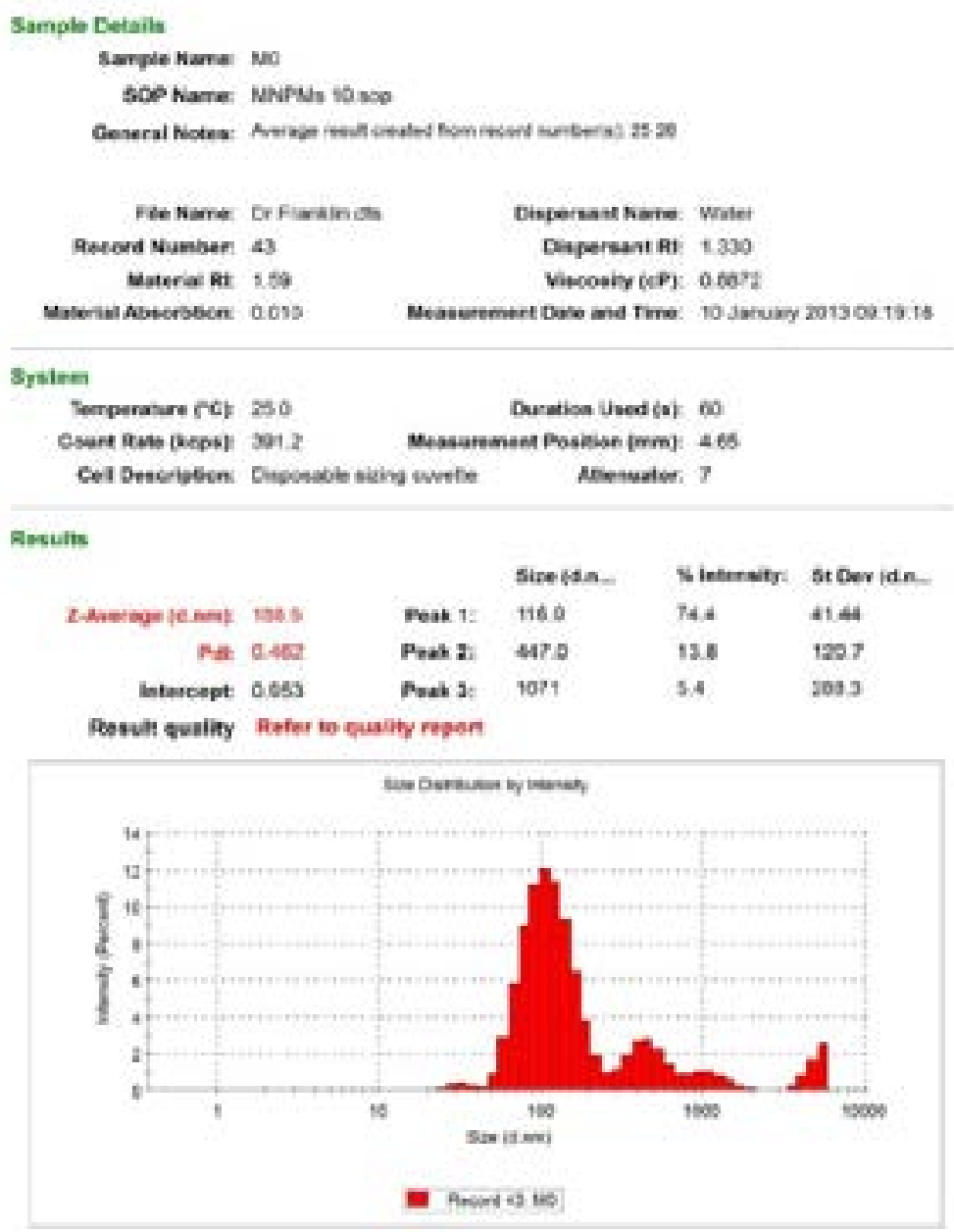

Figure 1. Photon correlation spectroscopy (PCS) analysis result of caprol-based nanostructured lipid carrier loaded with artemether and lumefantrine. 
The results of thermal analysis are as shown in Table 2 and Figures 2a-d. From Table 2, it could be seen that the individual drugs and lipid components had higher melting peak, artemether $\left(92.5^{\circ} \mathrm{C}\right)$, lumefantrine $(163.4$ $\left.{ }^{0} \mathrm{C}\right)$, but that of drug-loaded lipid matrix reduced to $\left(91.8^{\circ} \mathrm{C}\right)$. The lower enthalpy of drug loaded lipid matrix suggests that the formulation can produce matrix of lower crystallinity. Reduction in enthalpy generally suggests less crystallinity of lipid matrices ${ }^{36-41}$. In effect, this will culminate in greater bioavailability of the drug since it will exhibit better dissolution properties.

a

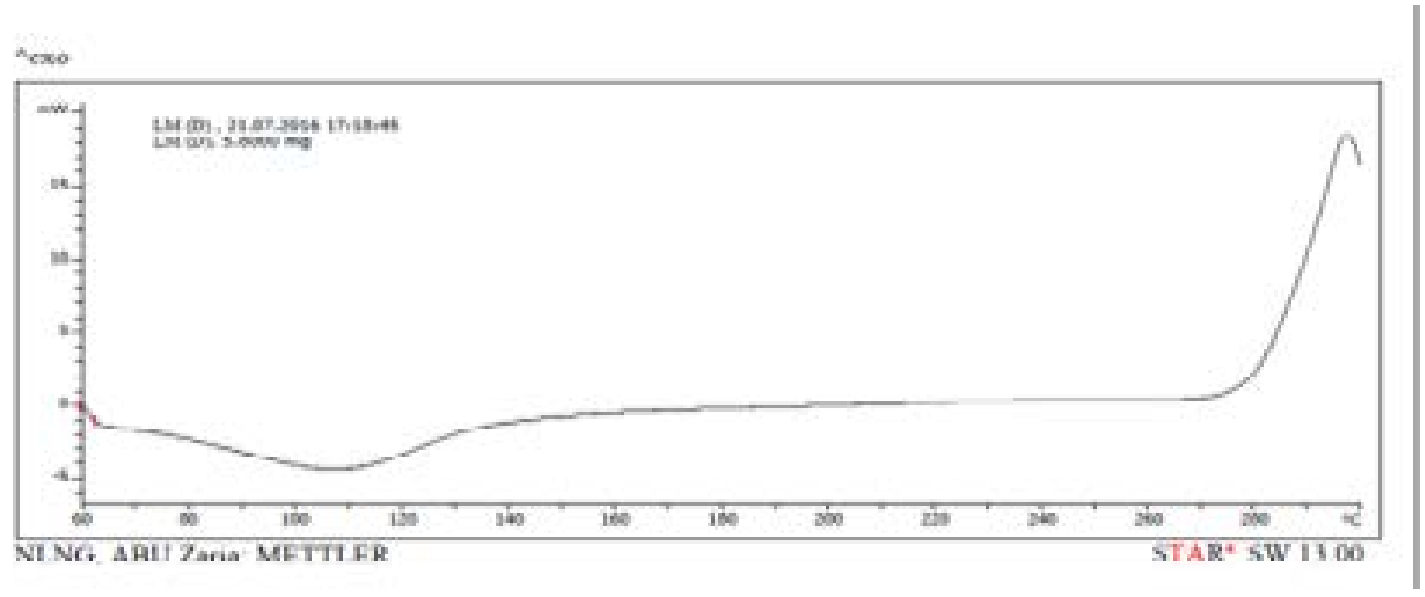

b

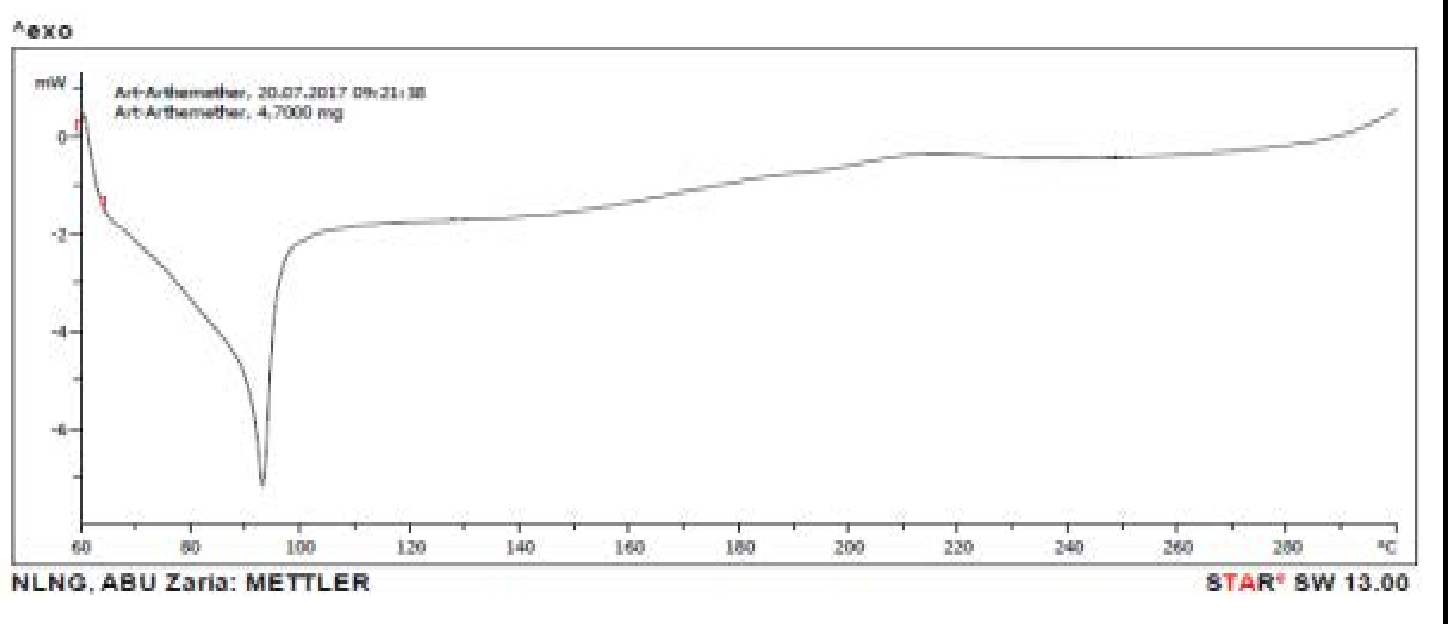

c

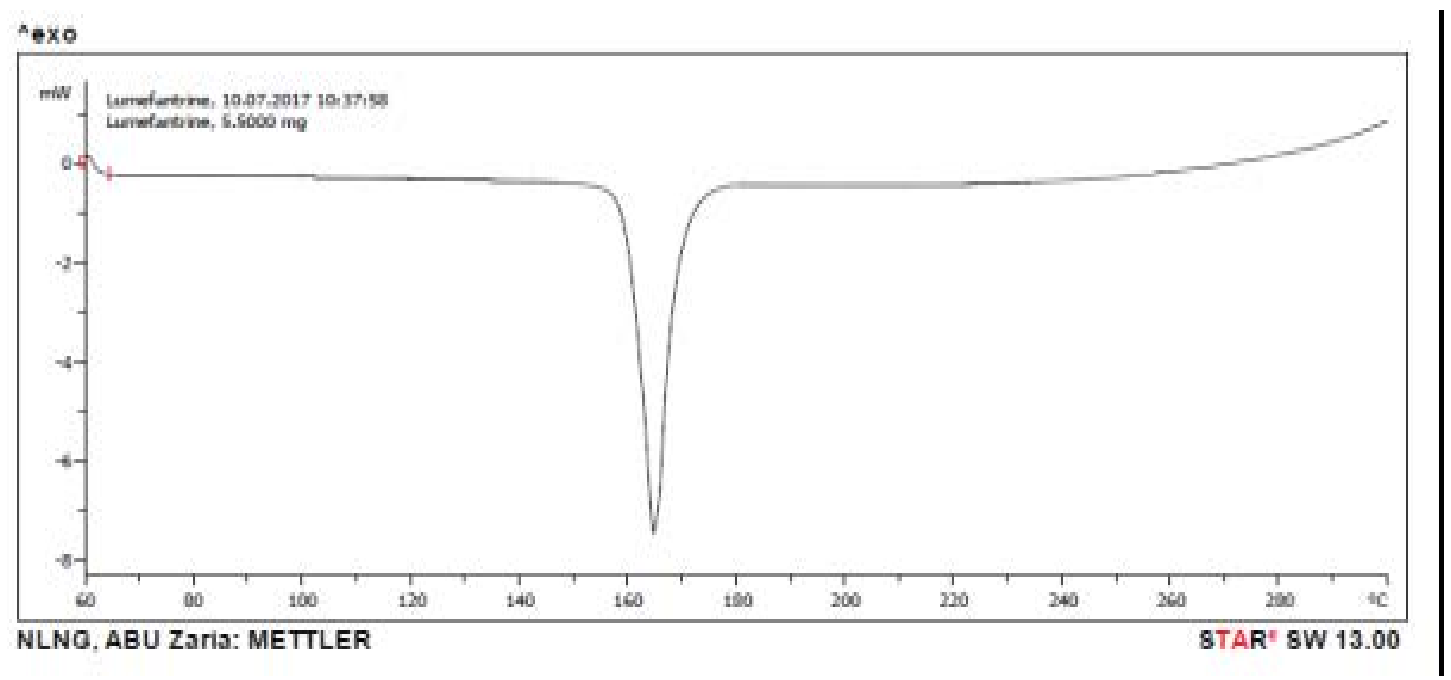




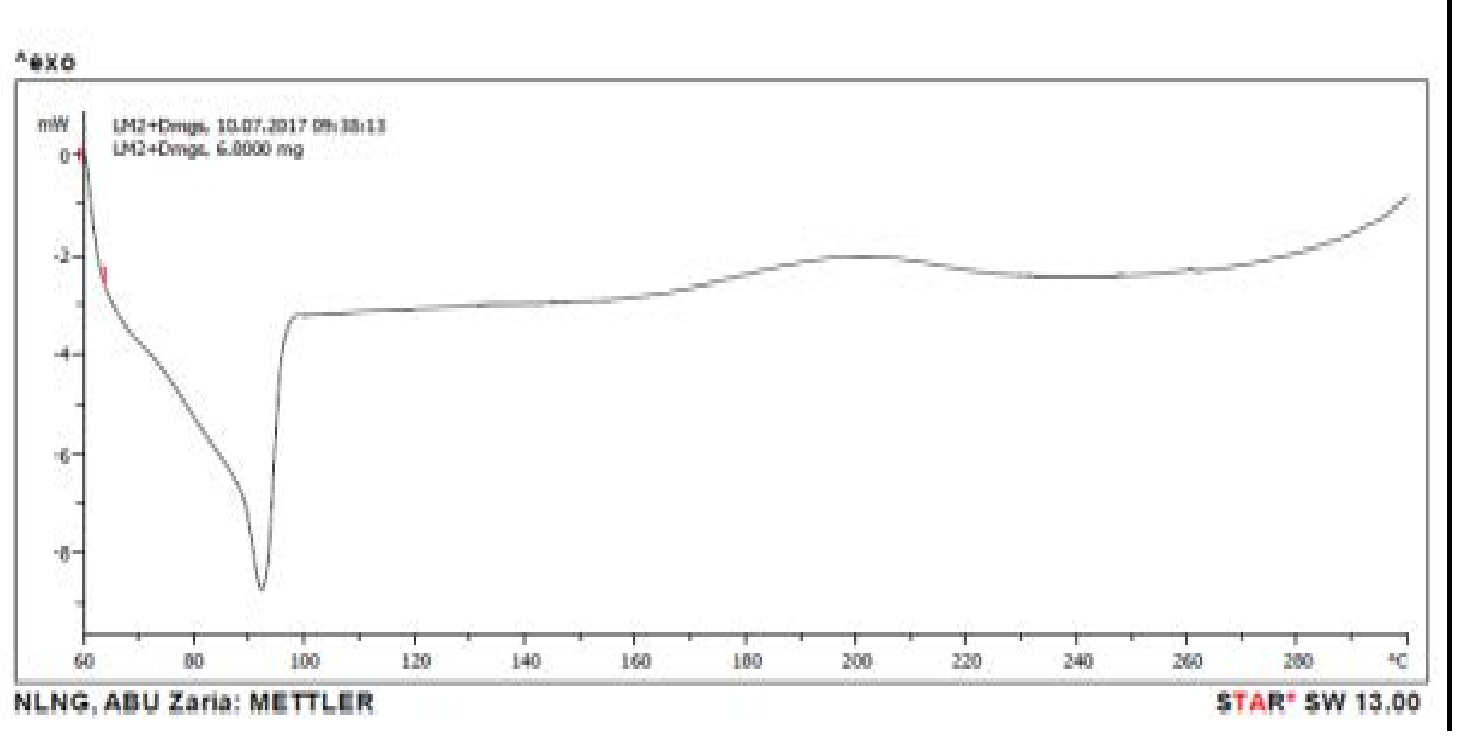

Figure 2: Differential scanning calorimetry (DSC) thermogram of (a) structured Phospholipid-modified beeswax-based lipid matrix structured with caprol-PGE $860\left(\mathrm{LM}_{3}\right)$, (b) artemether, (c) lumefantrine, and (d) artemether and lumefantrine co-loaded lipid matrix.

Table 2: Thermal properties (DSC profiles) of drugs, plain and drug-loaded lipid matrices

\begin{tabular}{lcll}
\hline Sample & $\begin{array}{c}\text { Melting } \\
\text { peak }\end{array}$ & $\begin{array}{l}\text { Enthalpy } \\
(\mathbf{m W} / \mathbf{m g})\end{array}$ & Type of peak \\
& $\left({ }^{\circ} \mathbf{C}\right)$ & & \\
\hline & 107.5 & -4.5 & Endothermic \\
& 278.3 & 2.1 & Exothermic \\
$\mathrm{LM}_{3}$ & 92.5 & -7.2 & Endothermic \\
Artemether & 163.4 & -7.5 & Endothermic \\
$\mathrm{Lumefantrine}$ & 91.8 & -8.9 & Endothermic \\
\hline $\mathrm{LM}$ & & &
\end{tabular}

Fourier transform infra-red (FT-IR) spectroscopic analysis of plain and drug-loaded lipid matrices Table 3 shows the compilation of the FT-IR results presented in Figures 3 and 4. It shows the major functional groups of the lipid constituents, the individual drugs, drug-loaded lipid matrix and that of the formulation. With all the major peaks which were seen in each of these components still showing even after the drug in- corporation is an indication that the drug and the excipients are compatible since no major interaction occurred between the functional groups of the various components hence the appearance of the major peaks in the FT-IR spectrum. The overall FT-IR spectra of the drugs and all the excipient used in the formulation suggested absence of any incompatibility between the drug and the excipients ${ }^{31}$. 
Table 3: FT-IR profiles of excipients, drugs and formulations

\begin{tabular}{|c|c|c|}
\hline Material & Principal peak $\left(\mathrm{cm}^{-1}\right)$ & Type of bond \\
\hline $\mathrm{LM}_{1}$ & $\begin{array}{l}3381.12 \\
3107.06 \\
2894.76 \\
1690.44 \\
1566.92 \\
1470.42 \\
887.56 \\
547.88 \\
\end{array}$ & $\begin{array}{l}\mathrm{O}-\mathrm{H} \text { bond vibration } \\
\mathrm{N}-\mathrm{H} \text { bond vibration } \\
\text { Carboxylic acid } \mathrm{C}-\mathrm{OH} \text { vibration } \backslash \\
\mathrm{C}=\mathrm{C} \text { bond vibration } \\
\mathrm{Conjugated} \mathrm{C}=\mathrm{C} \text { bond vibration } \\
-\mathrm{CH}_{3} \text { bond bending } \\
\text { Aromatic } \mathrm{C}-\mathrm{H} \text { out of plane bend } \\
\mathrm{C}-\mathrm{Br} \text { bond vibration }\end{array}$ \\
\hline Caprol-PGE 860 & $\begin{array}{l}3678.34,3643.60 \\
1593.94 \\
1227.24 \\
1007.22 \\
798.78,733.16\end{array}$ & $\begin{array}{l}\mathrm{O}-\mathrm{H} \text { stretching } \\
\text { Aromatic } \mathrm{C}=\mathrm{C} \text { bond vibration } \\
-\mathrm{C}=\mathrm{C}-\text { stretching } \\
\text { Amine group } \mathrm{C}-\mathrm{N} \text { bond vibration } \\
\mathrm{C}-\mathrm{Cl} \text { bond vibration }\end{array}$ \\
\hline $\mathrm{LM}_{3}$ & $\begin{array}{l}3601.14,3446.74 \\
3230.58,3049.16 \\
1393.22 \\
517.00\end{array}$ & $\begin{array}{l}\mathrm{O}-\mathrm{H} \text { bond vibration } \\
\mathrm{N}-\mathrm{H} \text { bond vibration } \\
\mathrm{C}-\mathrm{O} \text { bond vibration } \\
\mathrm{C}-\mathrm{Br} \text { bond vibration }\end{array}$ \\
\hline Artemether & $\begin{array}{l}3940.82 \\
3110.92 \\
3045.30 \\
2705.62 \\
1655.70 \\
1377.78,1130.74\end{array}$ & $\begin{array}{l}\mathrm{O}-\mathrm{H} \text { stretching } \\
\mathrm{N}-\mathrm{H} \text { stretching } \\
-\mathrm{C}-\mathrm{H} \text { streching } \\
\mathrm{O}=\mathrm{C}-\mathrm{H} \text { stretching } \\
\mathrm{C}=\mathrm{O} \text { vibration } \\
\mathrm{C}-\mathrm{O} \text { vibration } \\
\end{array}$ \\
\hline Lumefantrine & $\begin{array}{l}3759.40 \\
3477.62 \\
2956.52 \\
1566.92 \\
1443.40 \\
1354.62 \\
1076.70 \\
887.56 \\
486.12\end{array}$ & $\begin{array}{l}\mathrm{O}-\mathrm{H} \text { stretching } \\
\mathrm{N}-\mathrm{H} \text { stretching } \\
\mathrm{O}=\mathrm{C}-\mathrm{H} \text { stretching } \\
\text { Aromatic } \mathrm{C}=\mathrm{C} \text { bond vibration } \\
-\mathrm{CH}_{3}-\text { bond bending } \\
\mathrm{C}-\mathrm{O} \text { vibration } \\
\text { Amine group } \mathrm{C}-\mathrm{N} \text { bond vibration } \\
\text { Aromatic } \mathrm{C}-\mathrm{H} \text { out of plane bend } \\
\mathrm{C}-\mathrm{Cl} \text { bond vibration }\end{array}$ \\
\hline $\mathrm{LM}_{3}+$ Drugs & $\begin{array}{l}3879.06,3724.66 \\
3419.72,3222.86 \\
2956.52 \\
2736.50 \\
1597.80 \\
1412.52 \\
821.94 \\
578.76 \\
455.24\end{array}$ & $\begin{array}{l}\mathrm{O}-\mathrm{H} \text { stretching } \\
\mathrm{N}-\mathrm{H} \text { stretching } \\
-\mathrm{C}-\mathrm{H} \text { stretching } \\
\mathrm{O}=\mathrm{C}-\mathrm{H} \text { stretching } \\
\text { Aromatic } \mathrm{C}=\mathrm{C} \text { bond vibration } \\
-\mathrm{CH}_{3}-\text { bond bending } \\
\text { Aromatic } \mathrm{C}-\mathrm{H} \text { out of plane bend } \\
\mathrm{C}-\mathrm{Br} \text { bond vibration } \\
\mathrm{C}-\mathrm{Cl} \text { bond vibration }\end{array}$ \\
\hline $\operatorname{NLC}\left(M_{0}\right)$ & $\begin{array}{l}3689.92 \\
2246.28 \\
1783.08 \\
1659.56 \\
1536.04 \\
1412.52 \\
1323.74 \\
1045.82 \\
887.56 \\
\end{array}$ & $\begin{array}{l}\mathrm{O}-\mathrm{H} \text { stretching } \\
\mathrm{C}=\mathrm{N} \text { stretching } \\
\text { Vinyl ester bond vibration } \\
\mathrm{C}=\mathrm{C} \text { bond vibration } \\
\text { Aromatic } \mathrm{C}=\mathrm{C} \text { bond vibration } \\
-\mathrm{CH}_{3} \text { - bond bending } \\
\mathrm{C}-\mathrm{O} \text { vibration } \\
\text { Amine group } \mathrm{C}-\mathrm{N} \text { bond vibration } \\
\text { Aromatic } \mathrm{C}-\mathrm{H} \text { out of plane bend }\end{array}$ \\
\hline
\end{tabular}




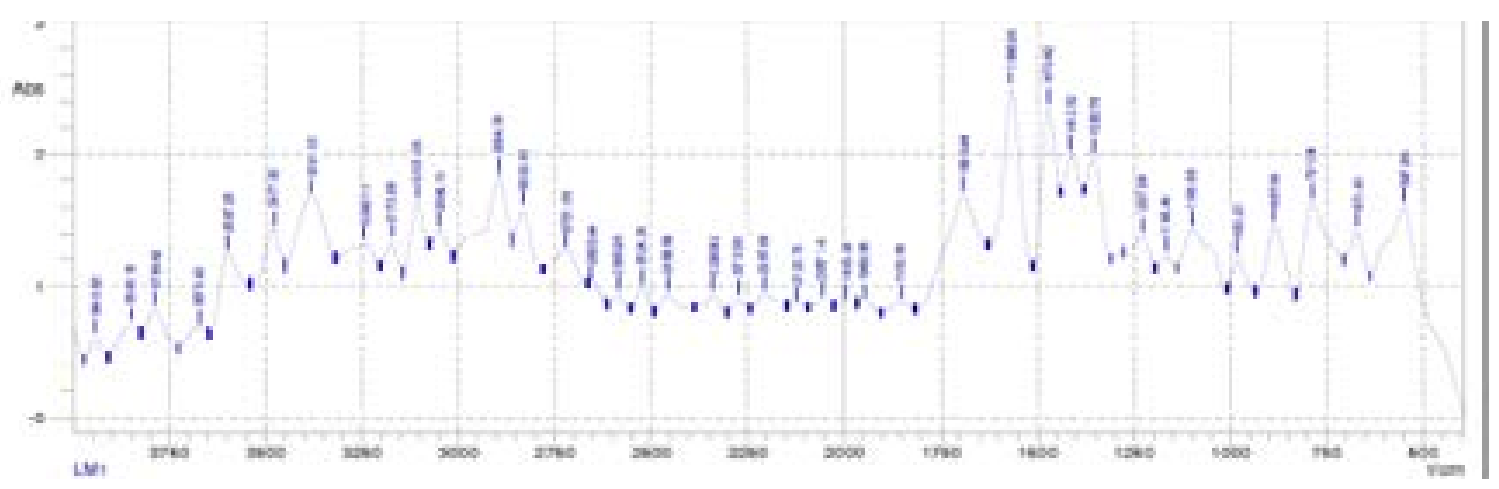

a

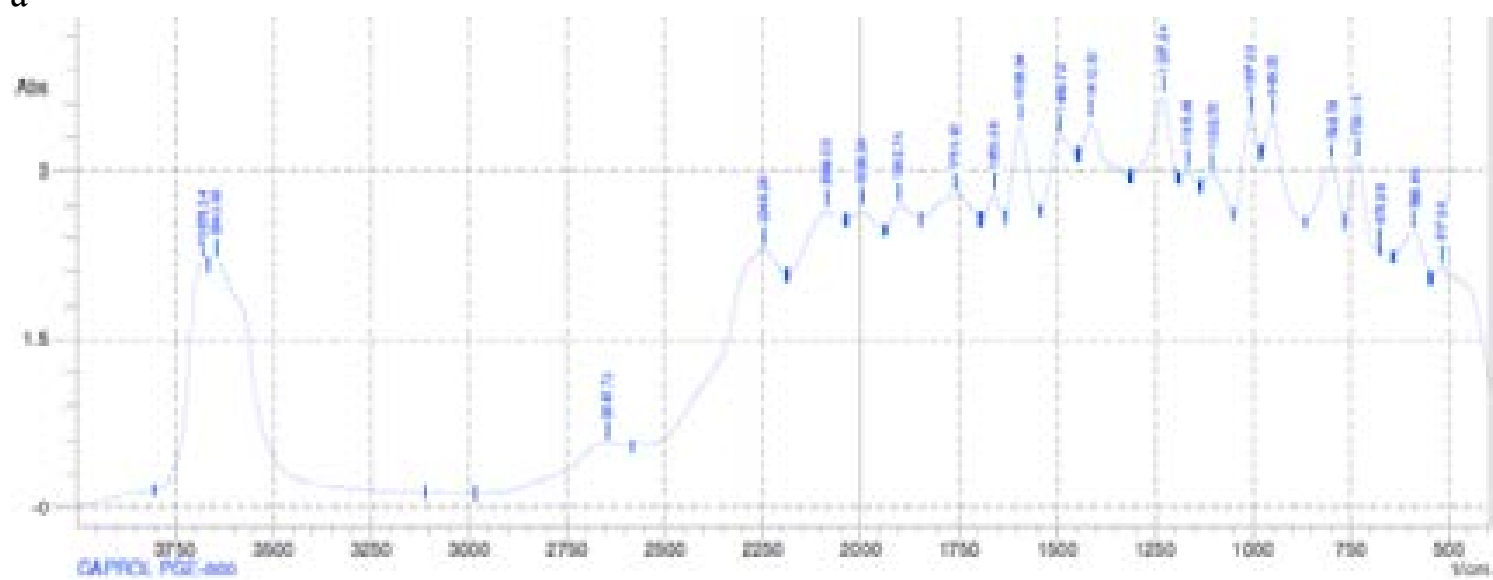

$\mathrm{b}$

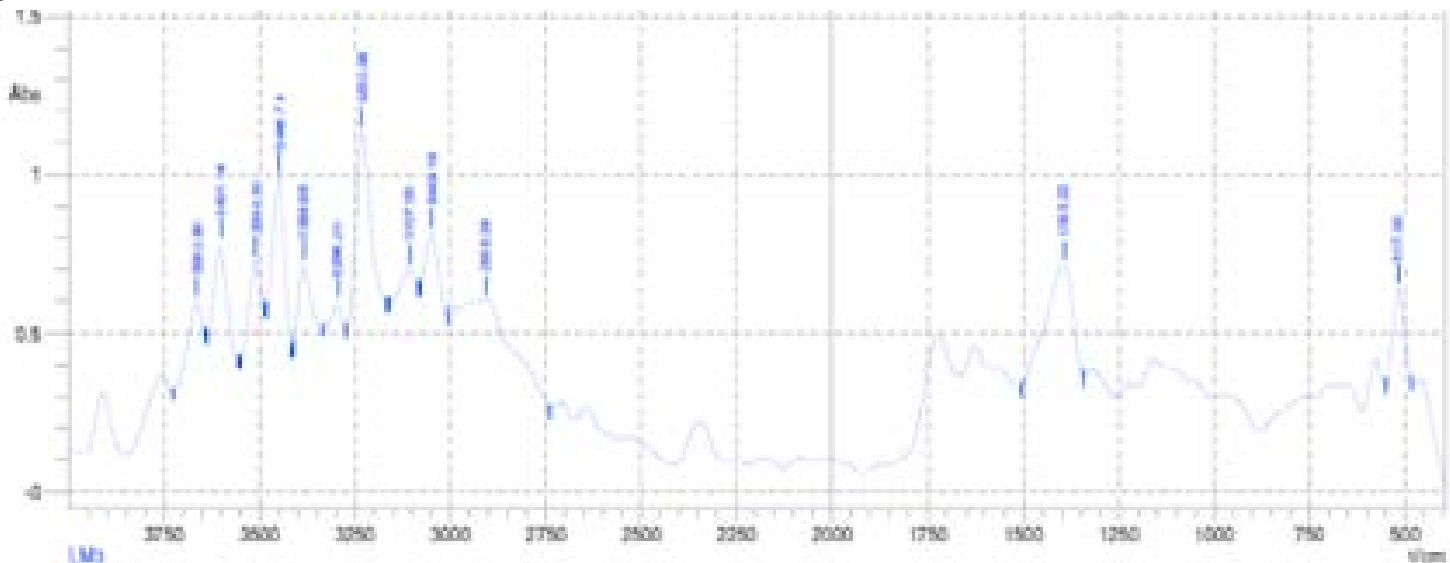

c

Figure 3: Fourier transform infra-red (FT-IR) spectrum of (a) lipid matrix based on beeswax and Phospholipon ${ }^{\circledR} 90 \mathrm{H}(\mathrm{P} 90 \mathrm{H})\left(\mathrm{LM}_{1}\right)$, (b) caprol-PGE 860 and (c) Phospholipid-modified beeswax-based lipid matrix structured with caprol-PGE $860\left(\mathrm{LM}_{3}\right)$. 


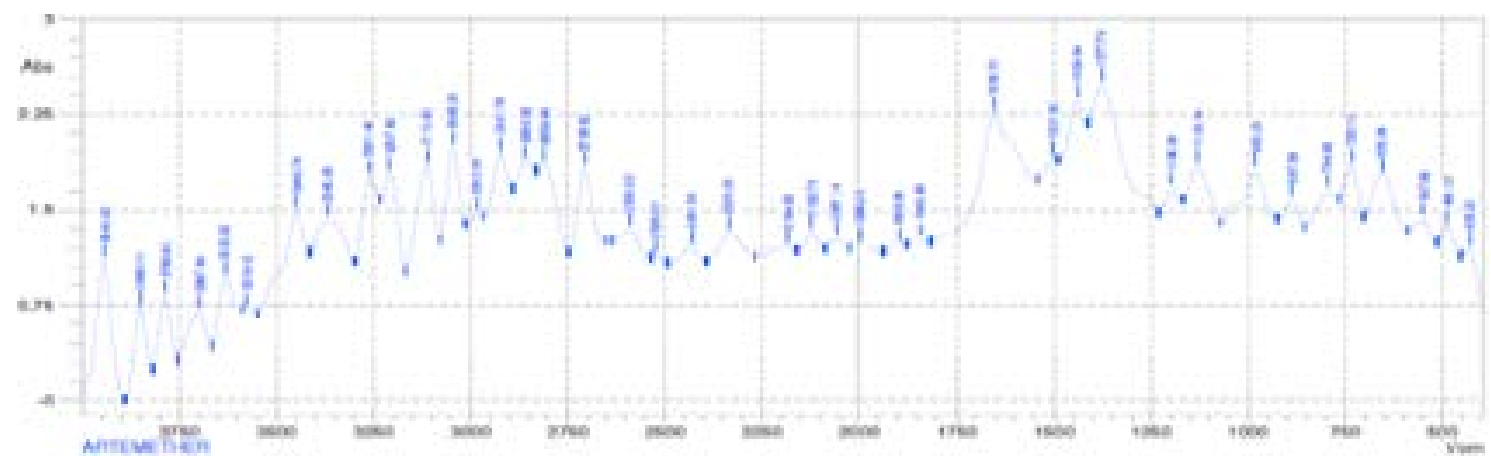

a

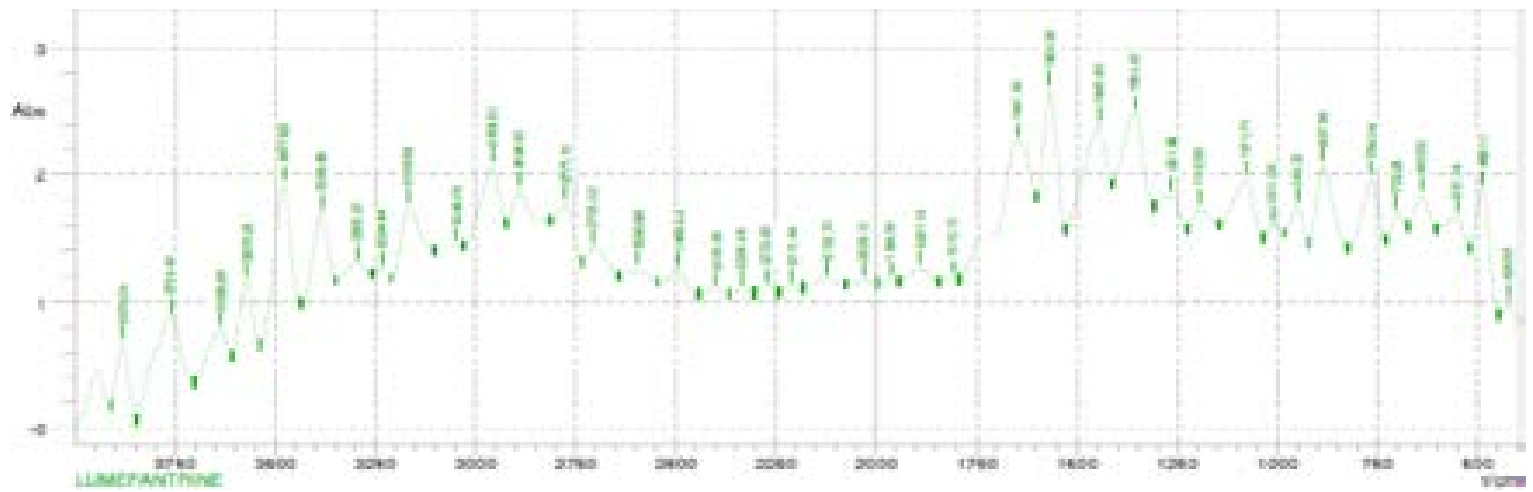

b

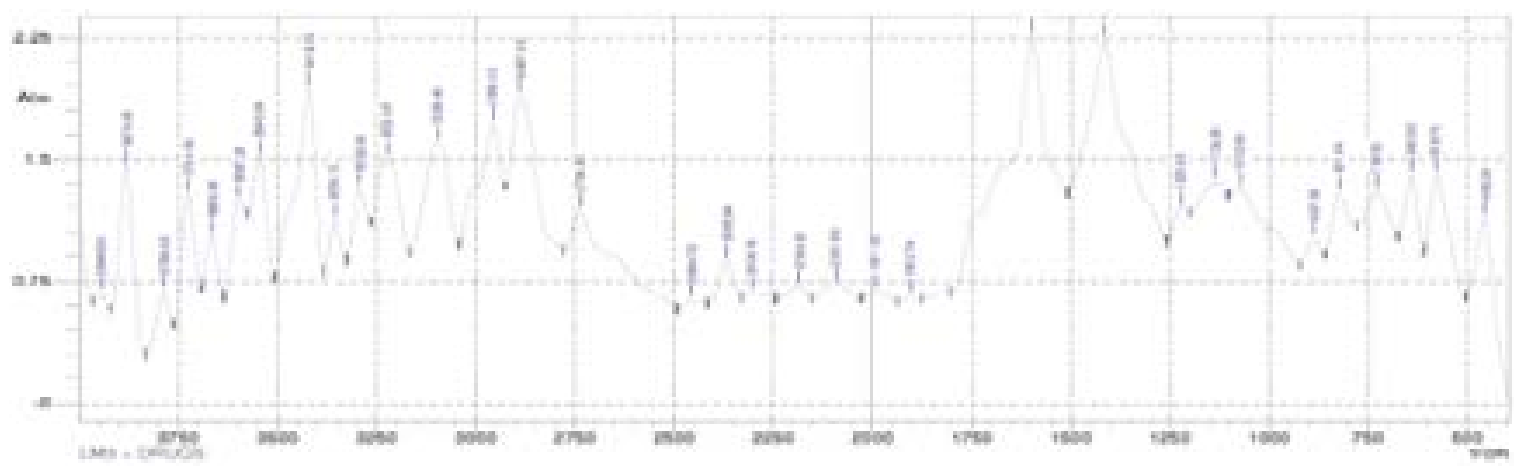

c

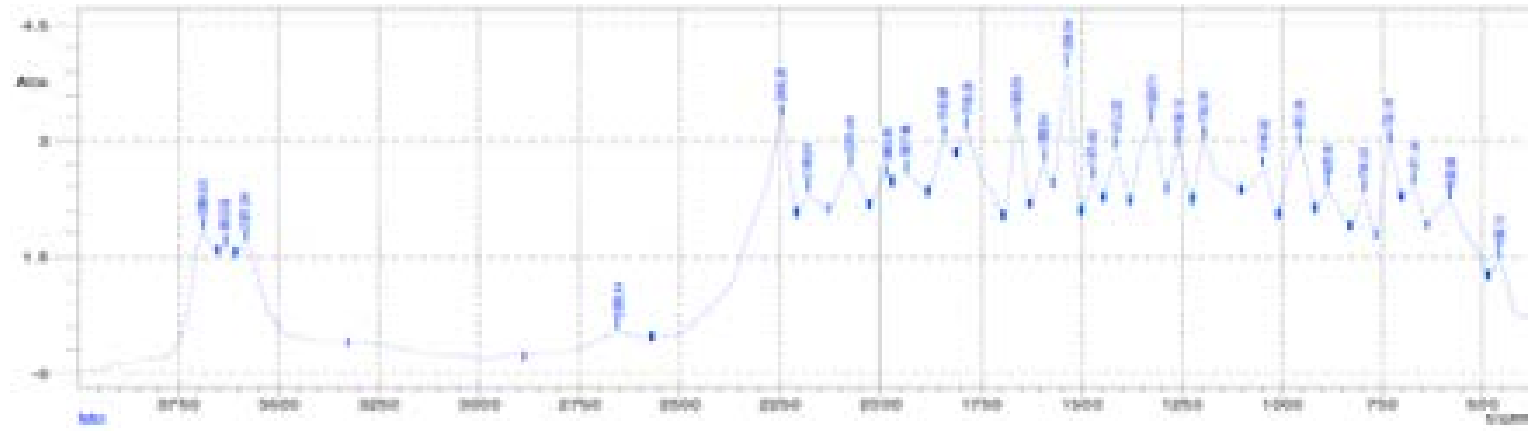

d

Figure 4: Fourier transform infra-red (FT-IR) spectrum of (a) artemether, (b) lumefantrine, (c) lipid matrix loaded with artemether and lumefantrine and (d) caprol-based NLC formulation containing artemether and lumefantrine. 


\section{Antimalarial activity of the NLC}

This shows the effectiveness of the treatments in eradicating parasitemia. From the results obtained as shown in Table 4, it was observed that the formulation that showed the same result as the standard treatment was more effective than chloroquine and the untreated control. On day 3 post inoculation, a mouse died in the groups treated with NLC (Mo), coartem $^{\circledR}$ and chloro- quine phosphate but after the initiation of therapy, NL$\mathrm{C}(\mathrm{Mo})$ and coartem $^{\circledR}$ were able to prevent further loss of the animals but two more and four animals died in the groups treated with chloroquine phosphate and distilled water, respectively. This is consistent with a recent study where Plasmodium berghei-infected mice treated with artemether and lumefantrine co-loaded NLCs showed better antimalarial activity with respect to survivability period ${ }^{17}$.

Table 4: Survivability in mice treated with caprol-based nanostructured lipid carrier

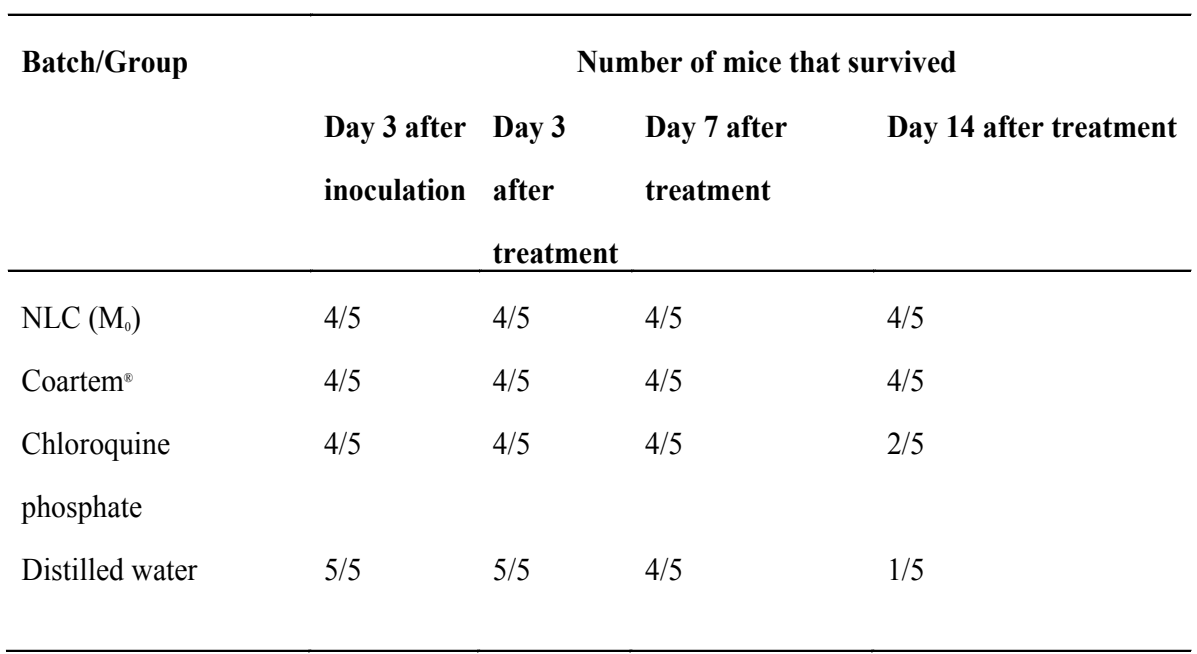

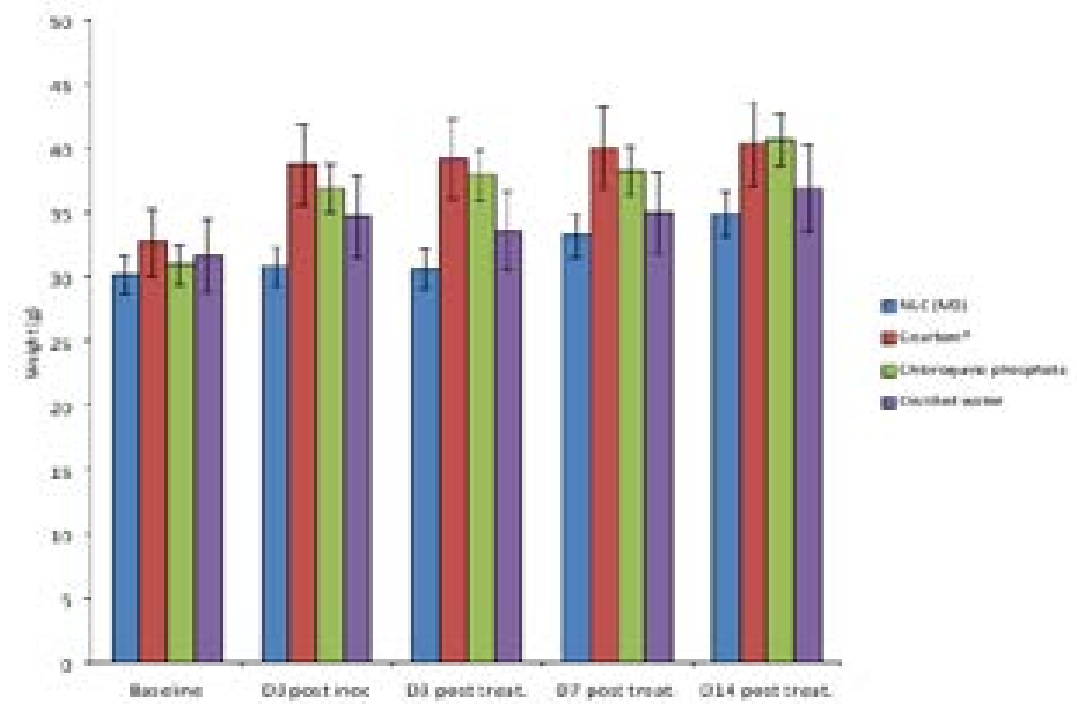

Figure 5: Effect of the formulations on the weight of the mice.

Figure 5 indicates the ability of the treatment to handle the worsening state of malaria in the mice which manifests as an increase in the weight (due to increase in the size of spleen, liver and possibly other blood-forming tissues). From the result, coartem $^{\circledR}$ appeared to be more effective in this task followed by Mo. Even though weight of animals in this group all increased, it was at a lower rate when compared to the groups treated with chloroquine and distilled water. 


\section{Hematological properties of the NLC}

From the result of the overall hematological studies carried out on the animals (Figures 6-9), it was noticed that the formulations $\left(\right.$ coartem $^{\circledR}$, chloroquine and Mo) were able to continually bring down the parasitemia level unlike what was observed in the untreated group. Also, from the result, it was observed that coartem ${ }^{\circledR}$ and chloroquine appeared to be more drastic at the early stage of treatment but the NLC (Mo) proved to be much more efficacious. The coartem ${ }^{\mathbb{R}}$ and chloroquine were more drastic in the reduction of parasitemia, restoration of normal hemoglobin level $(12.0-17.5 \mathrm{~g} / \mathrm{dl})$ after 14 days post-treatment and restoration of normal packed cell volume but at a point after days post treat- ment, recrudescence set in and both the hemoglobin and packed cell volume started to decrease after day 7 post-treatment and the parasitemia level in the group treated with coartem ${ }^{\circledR}$ and chloroquine started to increase, while the level in the group treated with Mo group continued to decrease. This may be as a result of NLC formulation being able to sustain the release of the drugs in the body much more than the other two drug formulations, which is an advantage over the standard, as has been demonstrated in previous studies, where Plasmodium berghei-infected mice treated with artemether and lumefantrine co-loaded NLCs showed better antimalarial activity with respect to parasitemia progression ${ }^{17,29-31}$.

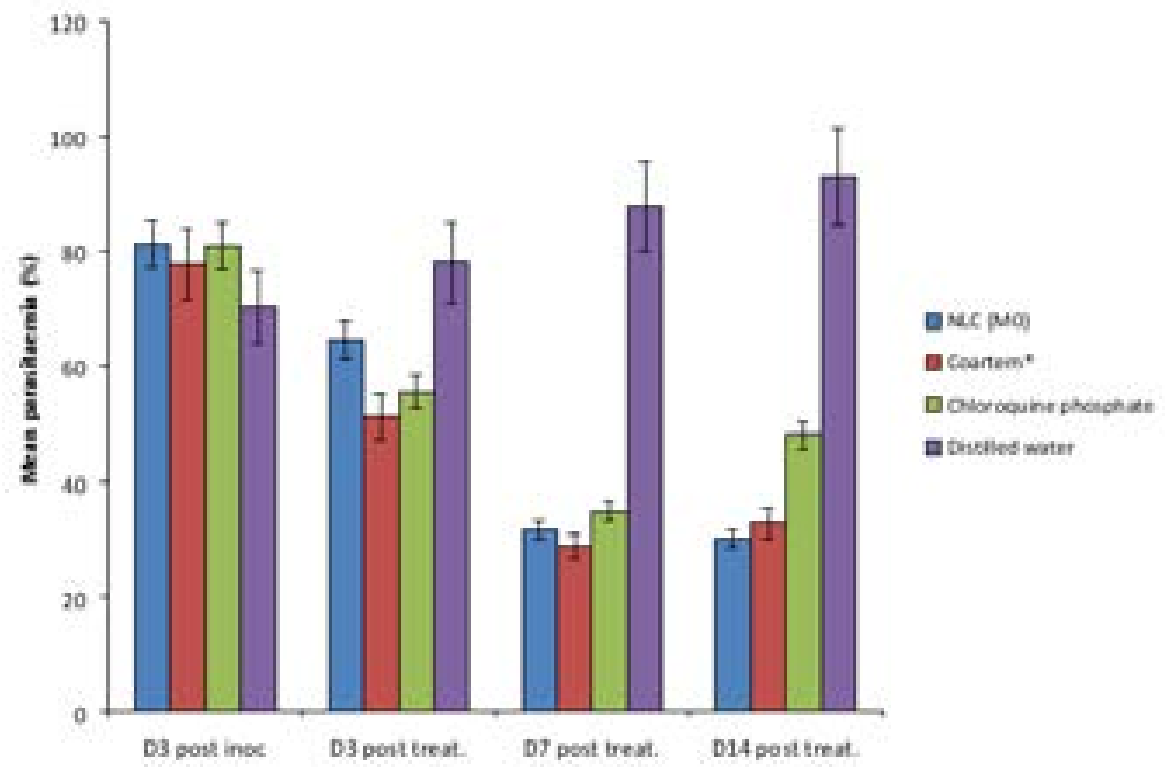

Figure 6: Mean percentage parasitemia in each group of the mice.

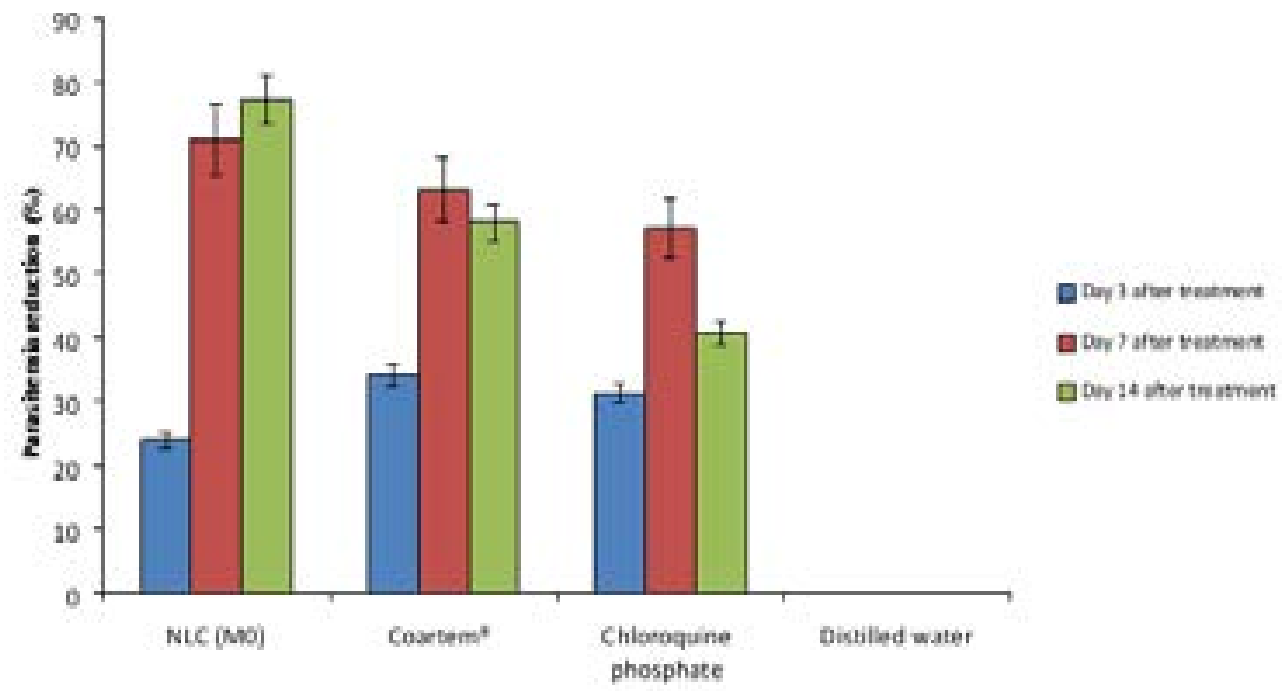

Figure 7: Percentage parasitemia reduction in the treatment groups. 


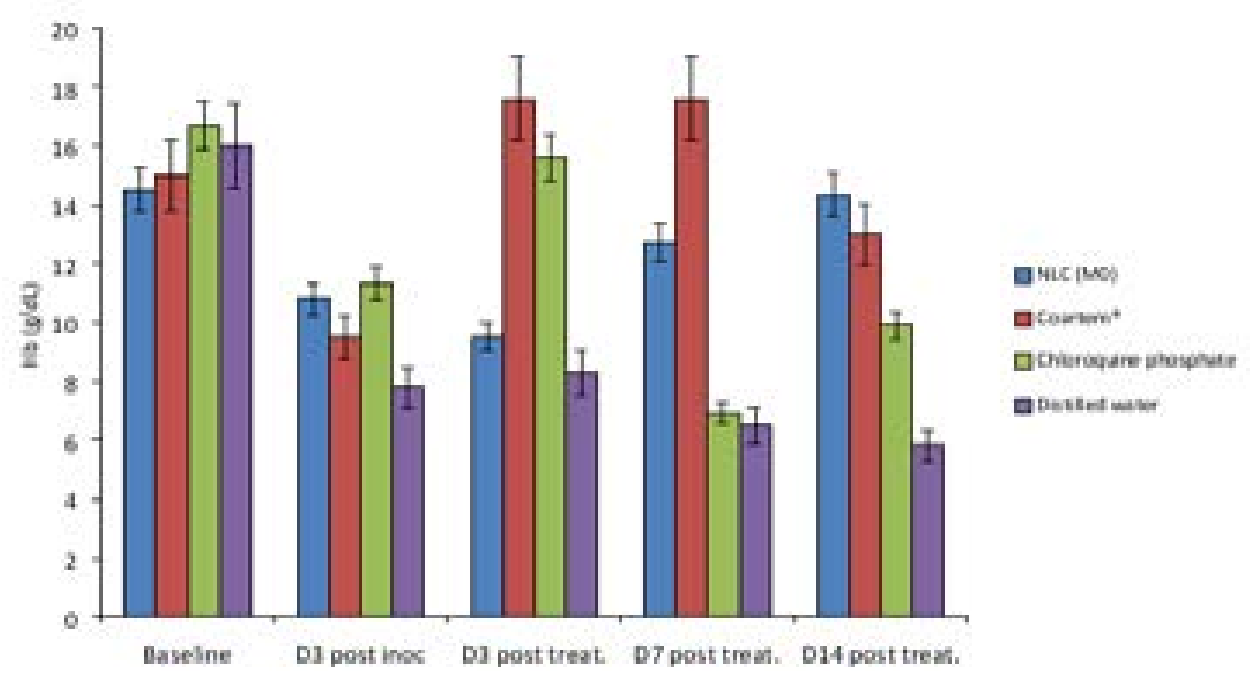

Figure 8: Effect of the formulations on hemoglobin of the mice.

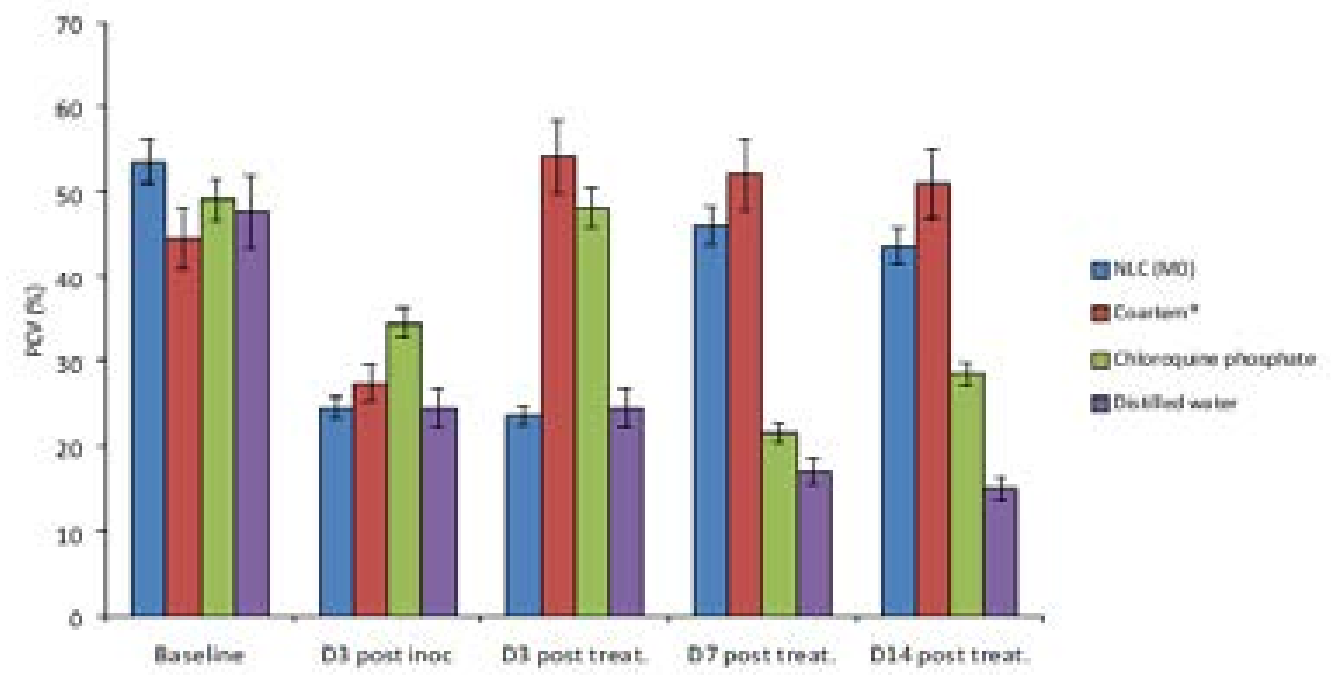

Figure 9: Effect of the formulations on packed cell volume of the mice.

\section{Histopathological analysis}

Table 5 is a summary of the histopathological study carried out on groups treated with the NLC formulation Mo (A), coartem ${ }^{\circledR}(B)$, chloroquine phosphate $(C)$, distilled water $(\mathrm{D})$ and group with no parasite inoculation
(E). From the results, it was observed that samples from group D showed severe periportal inflammation while those from groups $\mathrm{A}$ and $\mathrm{C}$ displayed moderate inflammation while samples from groups $\mathrm{B}$ and $\mathrm{E}$ showed no sign of periportal inflammation (Figures 10 and 11).

Table 5: Summary of histological lesions in the liver of rats from the experimental groups A-E.

\begin{tabular}{llllll}
\hline Lesions/groups & $\mathrm{A}$ & $\mathrm{B}$ & $\mathrm{C}$ & $\mathrm{D}$ & $\mathrm{E}$ \\
Periportal inflammation & ++ & - & ++ & ++++ & - \\
Kupffer cell hyperplasia & - & - & + & ++++ & - \\
& & & & & \\
Hemosiderosis/hemozoin & + & - & + & ++++ & - \\
$\begin{array}{l}\text { Hepatocytes vacuolation/ } \\
\text { necrosis }\end{array}$ & + & ++ & - & + & - \\
\hline
\end{tabular}

Keys: - absent, + mild, ++ moderate, +++ severe, ++++ very severe. 


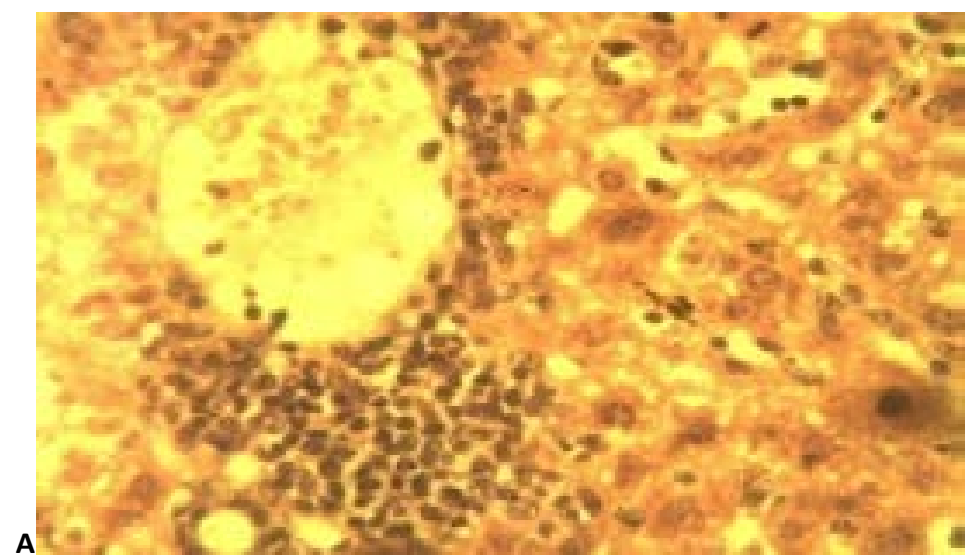

Figure 10: A photomicrograph of liver sections from experimental groups A $\left(\mathrm{M}_{\mathrm{o}}\right)$, showing periportal mononuclear cells infiltration. H and E X 400.
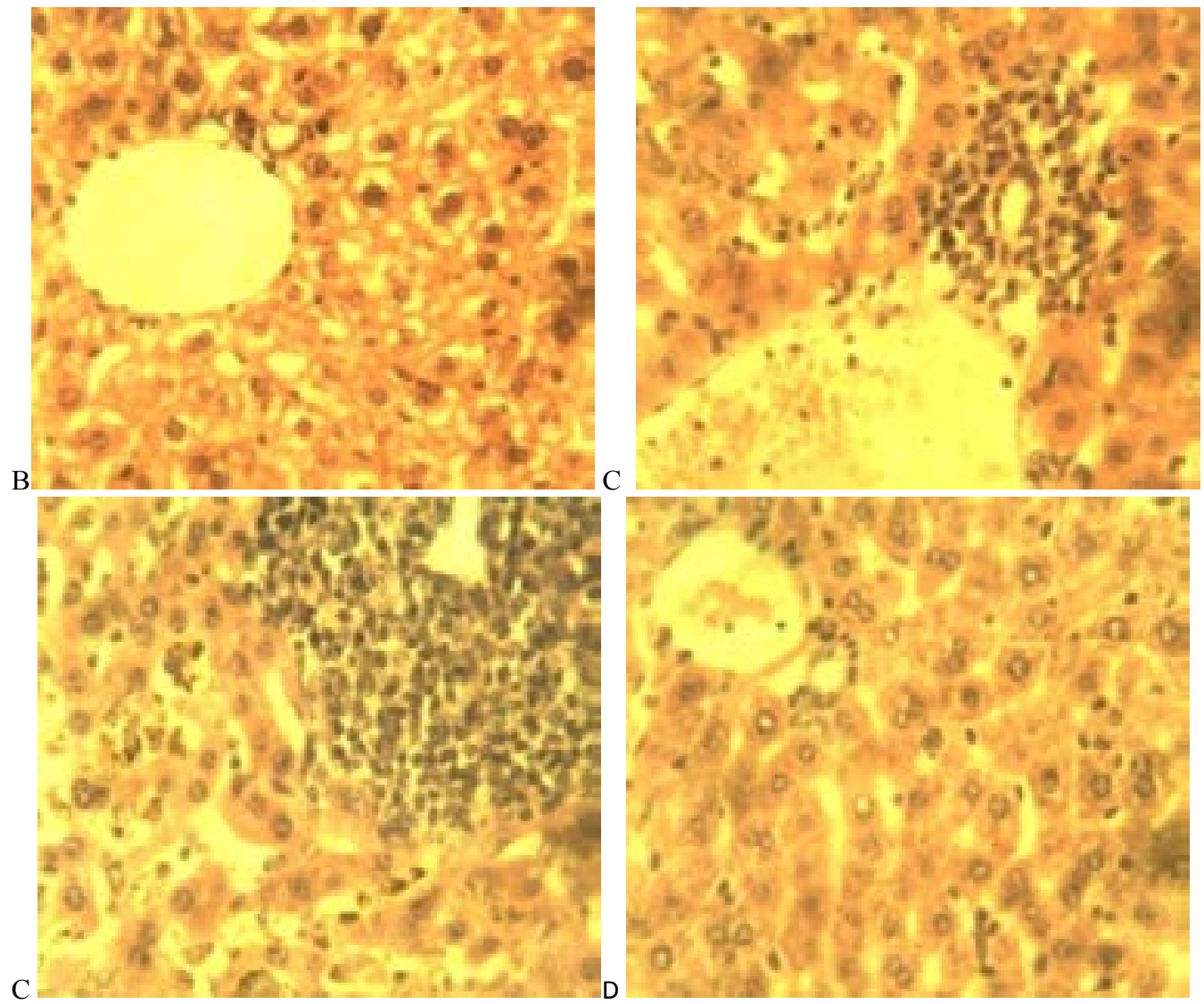

Figure 11: A photomicrograph of liver sections from experimental groups treated with $\left(\right.$ coartem $\left.^{B}\right)$ (B), (chloroquine phosphate) (C), (with no treatment) (D) and $\mathrm{E}$ (no parasite inoculation) showing periportal mononuclear cells infiltration in $\mathrm{C}$ and $\mathrm{D}$ (white arrows) while there is moderate vacuolar degenerations of hepatocytes (black arrows) and clearance of inflammatory reaction in $\mathrm{B}$. Note the severe hemosiderosis in $\mathrm{D}$ (blue arrows). The section in $\mathrm{E}$ is apparently normal. $\mathrm{H}$ and $\mathrm{E} \mathrm{x}$ 4.

Furthermore, it was also noticed that animals in group $\mathrm{D}$ had severe hemosiderosis and severe kupffer cell hyperplasia as well as mild hepatocyte vacuolation. Group A subjects had no kupffer cell hyperplasia but demonstrated mild hemosiderosis and hepatocyte vacuolation. Animals in Group B did not display any periportal inflammation, no hyperplasia nor hemosiderosis was observed but moderate hepatocyte vacuolation was noted.
Animals from Group $\mathrm{C}$ had mild hyperplasia, mild hemosiderosis and showed no sign of vacuolation. Group E samples showed no sign of inflammation, hyperplasia, hemosiderosis or hepatocyte vacuolation.

From the overall result of histopathology conducted on both liver and kidney of the different groups, it was noticed that, in grading of effectiveness of the differ- 
ent treatments in management of malaria in comparism the most effective followed by Mo and the chloroquine to the negative control group,coartem ${ }^{\circledR}$ appeared to be phosphate.

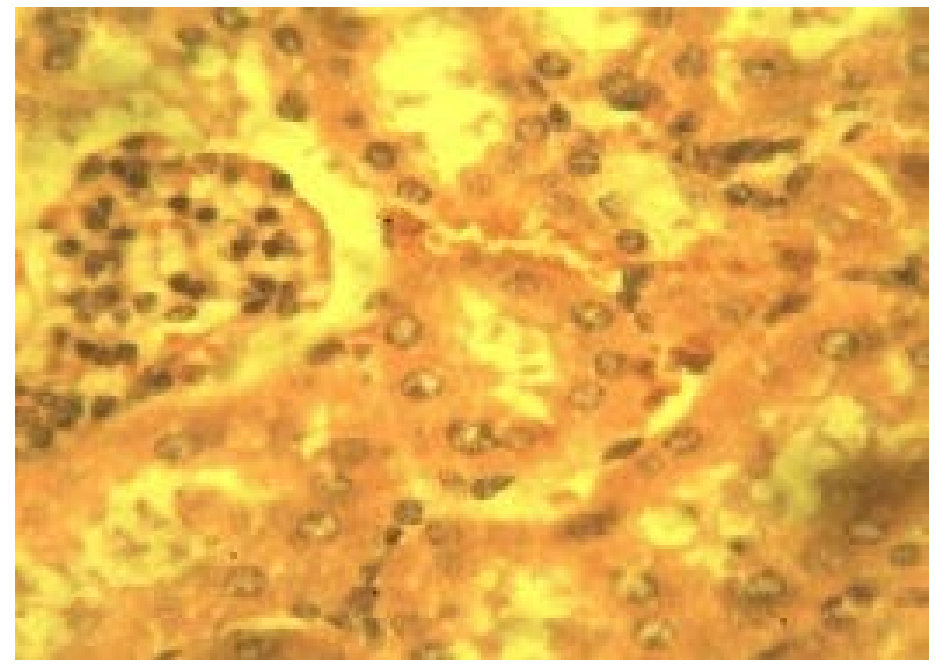

Figure 12: Photomicrograph of sections of the kidney from experimental rats of groups $\mathrm{A}\left(\mathrm{M}_{\mathrm{o}}\right)$. H and $\mathrm{E}$ x 400.
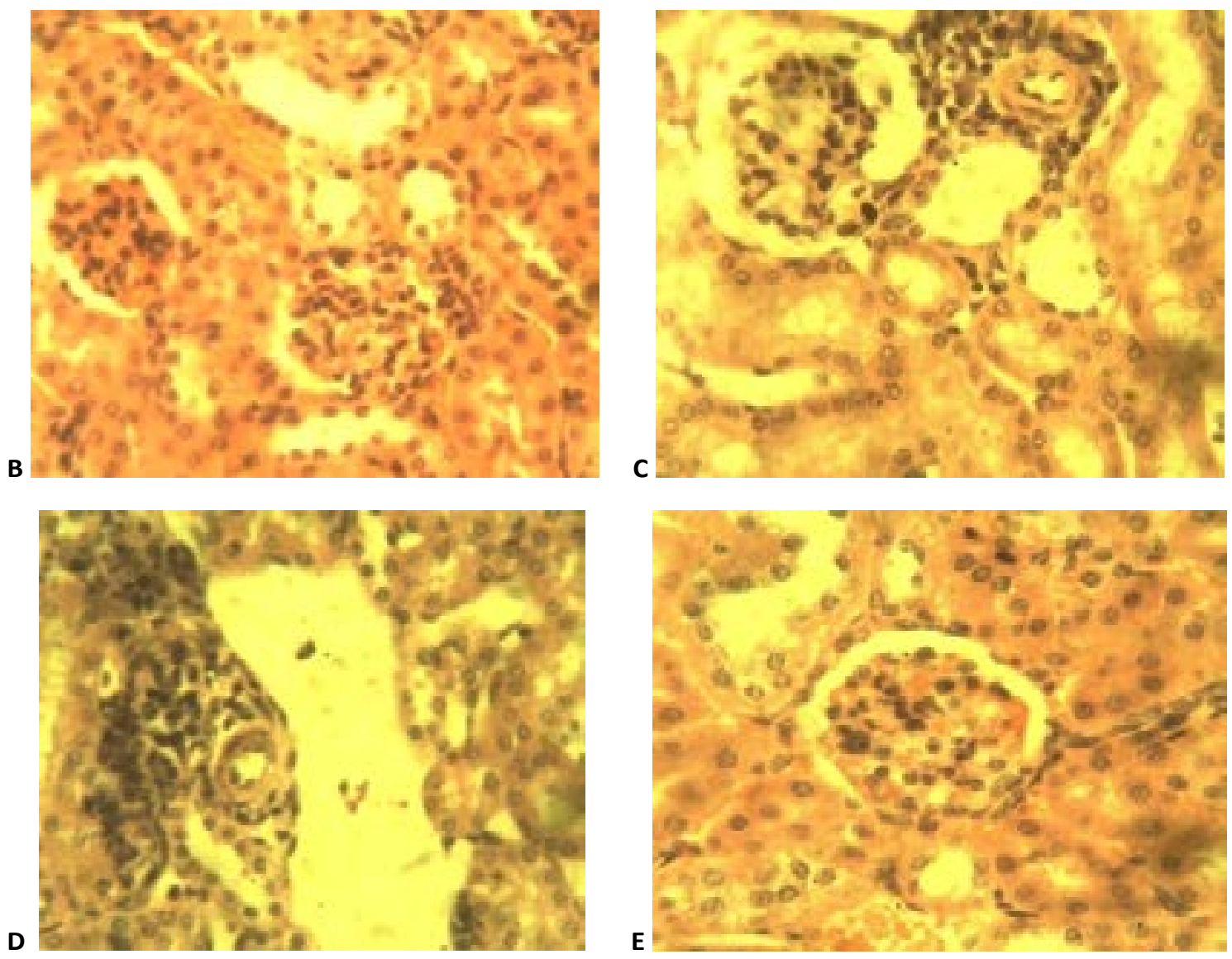

Figure 13: Photomicrograph of sections of the kidney from experimental rats of groups B (coartem $\left.{ }^{\circledR}\right)$, $\mathrm{C}$ (chloroquine phosphate), D (distilled water) and $\mathrm{E}$ (no parasitemia inoculation) showing perivascular mononuclear infiltration (vasculitis) in $\mathrm{C}$ and $\mathrm{D}$ (white arrows) while $\mathrm{B}$ and $\mathrm{E}$ shows no remarkable histologic change. $\mathrm{H}$ and $\mathrm{E} \times 400$. 


\section{Stability of the NLCs}

This test was performed to determine the $\mathrm{pH}$ stability of the SLMs batches when stored at room temperature and at different time intervals ${ }^{23}$. A good knowledge of the $\mathrm{pH}$ of maximum stability of a drug or its stability profile is important, especially in the design and formulation of a stable dosage form of the drug. The infor- mation will enable a formulation scientist to decide with certainty whether a stabilizer is necessary or not in the formulation of the drug ${ }^{23}$. The $\mathrm{pH}$ of the formulation was maintained during the period of storage- one day, one week, one month and three months, as shown in Figure 14, which is an indication of the stability of the formulation, consistent with our earlier report ${ }^{23}$.

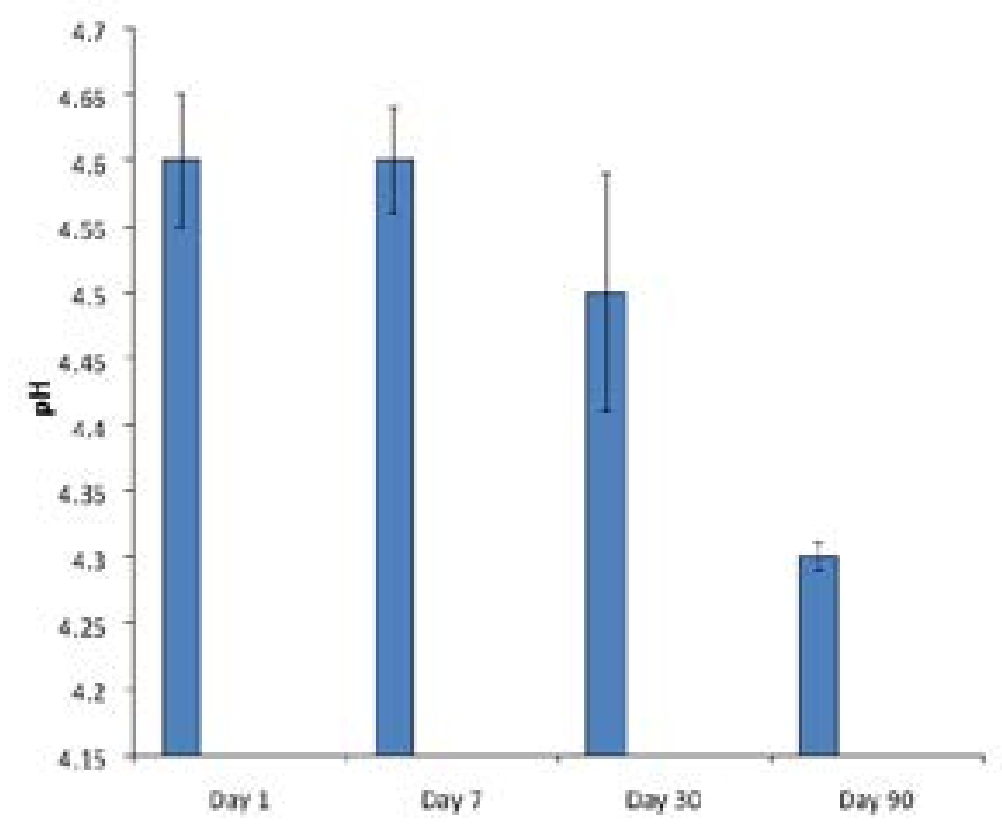

Figure 14: $\mathrm{pH}$ variation during storage of the $\operatorname{NLC}\left(\mathrm{M}_{0}\right)$.

\section{Conclusion}

In this study, artemether and lumefantrine encapsulated in nanostructured lipid carrier was successfully prepared using caprol-PGE 860.The developed NLCs possessed the desired particle size (mean $188.6 \mathrm{~nm}$ ) and particle size distribution. The NLC exhibited a better sustained inhibition of plasmodial growth in the malaria infected Wistar mice than the conventional preparation of artemether-lumefantrine in the market sample $\left(\right.$ coartem $^{\circledR}$ ) and chloroquine. The anti-malarial activities (reduction in parasitemia level, restoration of normal hemoglobin level and restoration of normal packed cell volume) of coartem $^{\circledR}$ and chloroquine phosphate started to reduce after day 7 post treatment but the formulation NLC (Mo) maintained its antimalarial effect throughout the duration of the study. The most important observation is the sustained release ability of the formulation which is an advantage over the conventional tablet $\left(\right.$ coartem $\left.^{\circledR}\right)$ as it offers us an option of having a formulation with better dosage regimen and more tolerable dose. Efficacy of the prepared NLCs in murine model of malaria infection suggests that this preparation could behave in similar fashion in humans though actual trials need to be carried out to justify this assertion. It may be posited that artemether-lumefantrine NLC is a promising option for use in the global battle to contain the scourge of severe malaria especially in malaria endemic countries.

\section{Conflict of interest}

All authors have approved the final manuscript and all declare they have no conflict of interest.

\section{Acknowledgements}

This research work received financial support from Tertiary Education Trust Fund (TETFund) (Grant no. TETFund/DR\&D/CE/NRF/STI/46/) by Government of Nigeria. Dr. Kenechukwu also acknowledges the support received from the African-German Network of Excellence in Science (AGNES), the German Federal Ministry of Education and Research (BMBF) and the Alexander von Humboldt Foundation $(\mathrm{AvH})$.

\section{References}

1. World Malaria Report. (2018). World Health Organization, Geneva, Switzerland. 
2. Mendis KN, David PH, Carter R. (1991). Antigenic polymorphism in malaria: is it an important mechanism for immune evasion? Immunol. Today. 12(3):34-7. 3. Hoffman SL, Vekemans J, Richie TL, Duffy PE. (2015). The march toward malaria vaccines. Vaccine. 33(Suppl 4): D13-D23.

4. Uduma EO, Ming H. (2018). Bioavailability and pharmacokinetics of dihydroartemisinin (DHA) and its analogs - mechanistic studies on its ADME. Curr. Pharmacol. Reports, 33-44.

5. White NJ. (2004). Antimalarial drug resistance. J. Clin. Invest. 113(8):1084-1092.

6. World Health Organization (WHO). (2001). Antimalarial drug combination therapy. Report of a technical consultation. WHO. Geneva, Switzerland. WHO/CDS/RBM 2001.35.

7. Rathod PK, McErlean T, Lee PC. (1997). Variations in frequencies of drug resistance in Plasmodium falciparum. Proc. Natl. Acad. Sci. U. S. A. 94:9389-9393. 8. Bloland PB, Ettling M, Meek S. (2000). Combination therapy for malaria in Africa: hype and hope. Bull. World Health Organ. 78:1378-1388.

9. White NJ, van Vugt M, Ezzet F. (1999). Clinical pharmacokinetics and pharmacodynamics of artemether-lumefantrine. Clin. Pharmacokinet. 37:105-125. 10. Wernsdorfer WH, Landgraf B, Kilimali VA. (1998). Activity of benflumetol and its enantiomers in fresh isolates of Plasmodium falciparum from East Africa. Acta Tropica. 70:9-15

11. White NJ. (1997). Assessment of the pharmacodynamic properties of antimalarial drugs in vivo. Antimicrob. Agents Chemother. 41: 1413-22

12. Duchêne, D, Gref R. (2016). Small is beautiful: Surprising nanoparticles. Int. J. Pharm. 502: 219- 231.

13. Tillotson JK. (2018). Advanced lipid-based drug delivery systems: solid lipid nanoparticles and nanostructured lipid carriers. Drug Dev. Delivery. 2:.32- 39

14. Kapoor H, Aquil M, Imam SS, Sultana Y, Ali A. (2019). Formulation of amlodipine nano lipid carrier: Formulation design, physicochemical and transdermal absorption investigation. J. Drug Deliv. Sci. Tech. 49: 209218

15. Shakeel K, Raisuddin S, Ali S, Imam SS, Rahman AA, Jain GK, Ahmad FJ. (2019). Development and in vitro/in vivo evaluation of artemether and lumefantrine co-loaded nanoliposomes for parenteral delivery. J. Liposome Res. 29: 35-43

16. Akansha M, Imam SS, Aqil M, Ahad A, Sultana Y, Ameeduzzafar, Ali A. (2016). Carvedilol nano lipid carriers: formulation, characterization and in vivo evaluation. Drug Deliv. 23(4):1486-1494.
17. Deepa P, Aditya NP, Murthy RSR. (2016). Development of artemether and lumefantrine co-loaded nanostructured lipid carriers: physicochemical characterization and in vivo antimalarial activity. Drug Deliv. 23(1): 123-129. DOI:10.3109/10717544.2014.905883.

18. Nnamani PO, Hansen S, Windbergs M, Lehr C-M. (2014). Development of artemether-loaded nanostructured lipid carrier (NLC) formulation for topical application. Int. J. Pharm. 477: 208-217.

19. Jennings V, Ghola SH, Thinemann AF. (2001) Characteristics of a novel solid lipid nanoparticle carrier systems based on binary mixture of lipid and solid lipids. Int. J. Pharm. 199: 161-177.

20. Didier LM. (2000) Rationale and application of lipid as pro-drug carriers, Eur. J. Pharm. Sci.11:2243255.

21. Attama AA, Kenechukwu FC, Onuigbo EB, Nnamani PO, Obitte NC, Finke JH, Pretor S, Muller-Goymann CC. (2016). Solid lipid nanoparticles encapsulating a fluorescent marker (coumarin 6) and anti-malarials - artemether and lumefantrine: evaluation of cellular uptake and anti-malarial activity. Eur. J. Nanomed. 8(3):129 -138.

22. Nnamani PO, Ugwu AA, Ibezim EC, Kenechukwu FC, Akpa PA, Ogbonna JDN, Obitte NC, Odo AN, Windbergs M, Lehr CM, Attama AA. (2016). Sustained-release liquisolid compact tablets containing artemether-lumefantrine as alternate-day regimen for malaria treatment to improve patient compliance. Int. J. Nanomed. 11:6365-6378.

23. Agbo CP, Umeyor CE, Kenechukwu FC, Ogbonna JDN, Chime SA, Charles L, Agubata CO, Ofokansi KC, Attama AA. (2016). Formulation design, in vitro characterizations and anti-malarial investigations of artemether and lumefantrine-entrapped solid lipid microparticles. Drug Dev. Ind. Pharm. 42(10):1708-21.

24. Onwurah NE. (2001). Introductory Biochemistry for Life Sciences, 1st ed., Immaculate Pub. Ltd., Enugu, Nigeria, p.21-49.

25. Umeyor, C.E., Okoye, I., Uronnachi, E.M., Okeke, T., Kenechukwu, F.C., Attama, A.A. (2020). Repositioning miconazole nitrate for malaria: Formulation of sustained release nanostructured lipid carriers, structure characterization and in vivo antimalarial evaluation. J. Drug Deliv. Sci. Tech. https://doi.org/10.1016/j. jddst.2020.102125

26. Attama AA, Schike BC, Muller-Goyman CC. (2006). Further characterization of theobroma oil-beeswax admixtures as lipid matrices for improved drug delivery systems. Eur. J. Pharm. Biopharm. 64: 294-306.

27. Yadzi S. (2007). Symmetrical 1,3-diglycerides as 
a lipid microparticle for controlling drug delivery. http;/ hdl.handle.net $/ 1813 / 5198$

28. Woodbury DJ, Miller C. (1990). Nystatin-induced liposome fusion: A versatile approach ion channel reconstitution into plannar bilayer. Biophysics J. 58833-839.

29. Priyanka P, Narsee M. (2016). Artemether-lumefantrine nanostructured lipid carriers for oral malaria therapy: Enhanced efficacy at reduced dose and dosing frequency. Int. J. Pharm. 511(1): 473-487.

30. Priyanka P, Shital S, Sulabha P, Aditua P, Shobhona, Vandana P. (2016). Nanostructured lipid carriers for artemether-lumefantrine combination for intravenous therapy of celebral malaria. Int. J. Pharm. 513: 504517.

31. Yufan M, Tingli L, Wen Z, Ying W, Ting C, Oibing M, Tao C. (2014). Enhanced antimalarial activity by a novel artemether-lumefantrine lipid emulsion for parenteral administration. Antimicrob Agents Chemother. 58(10): 5658-5665. doi:10.1128/AAC.01428-13.

32. Johnson M, Barauskas J, Norlin A, Tiberg F. (2006). Physicochemical and drug delivery aspect of lipid based crystalline nanoparticles: A case study of intravenously administered propofol. J. Nanosii. Nanotech. 6:3017-3024.

33. Muller RH, Mader K, Gohla S.H. (2000). Solid lipid nanoparticle for controlled delivery: A review of the art. Eur. J. Pharm. Biopharm. 50:161-177.

34. Kalja J, Wolfgang M, Markus D, Bunjes H,
Christoph J, Karsten M. (2004). Investigation of the structure of solid lipid nanoparticle (SLN) and oil-loaded solid lipid nanoparticle by photon correlation spectroscopy, field flow fractionation and transmission electron microscopy. J. Control. Rel. 95:217-227.

35. Muller RH, Mehnert W, Lucks JS, Schwars AZ, Freitas C, Ruhl D. (1995). Solid lipid nanoparticle (SL$\mathrm{N})$-An alternative for colloid carrier system for controlled drug delivery. Eur. J. Biopharm. 41:62-69.

36. Muller RH, Wissing SA, Radtke SA. (2002). Nanostructured lipid matrices for improved microencapsulation of drugs. Int. J. Pharm. 242:121-128.

37. Zhang X, Gan Y, Purdon CH, Smith EW. (2006). Solid lipid nanoparticle for topical drug delivery. Amer. J. Drug Deliv. 4(4):215-220.

38. Domb AJ. (1993). Liposphere for controlled delivery of substances. freepatentonline.com/5188837. html

39. Attama AA. (2009). Formulation and in vitro evaluation of a PEGylated microscopic lipospheres delivery system for ceftriaxone sodium. Amer. J. Drug Deliv. 16(8):448-457.

40. Domb AJ. (1995). Long-acting injectables oxytetracycline-liposphere formulation. Int. J. Pharm. 124(2): 271-278.

41. Attama AA, Schicke BC, Paepenmuller T, Muller-Goymann CC. (2007). Solid lipid nanoparticulate dispersions containing mixed lipid core and a polar heterolipid: Characterization. Eur. J. Pharm. Biopharm. $748-57$ 